\title{
Investigation of synovial fluid lubricants and inflammatory cytokines in the horse: a comparison of recombinant equine interleukin 1 beta-induced synovitis and joint lavage models
}

Amanda Watkins', Diana Fasanello', Darko Stefanovski ${ }^{2}$, Sydney Schurer ${ }^{1}$, Katherine Caracappa', Albert D'Agostino', Emily Costello ${ }^{3}$, Heather Freer ${ }^{4}$, Alicia Rollins ${ }^{4}$, Claire Read', Jin Su', Marshall Colville ${ }^{3}$, Matthew Paszek ${ }^{3}$, Bettina Wagner ${ }^{4}$ and Heidi Reesink ${ }^{1 *}$

\begin{abstract}
Background: Lameness is a debilitating condition in equine athletes that leads to more performance limitation and loss of use than any other medical condition. There are a limited number of non-terminal experimental models that can be used to study early inflammatory and synovial fluid biophysical changes that occur in the equine joint. Here, we compare the well-established carpal IL-1 $\beta$-induced synovitis model to a tarsal intra-articular lavage model, focusing on serial changes in synovial fluid inflammatory cytokines/chemokines and the synovial fluid lubricating molecules lubricin/proteoglycan 4 and hyaluronic acid. The objectives of this study were to evaluate clinical signs; synovial membrane and synovial fluid inflammation; and synovial fluid lubricants and biophysical properties in response to carpal IL-1 $\beta$ synovitis and tarsal intra-articular lavage.

Results: Hyaluronic acid (HA) concentrations, especially high molecular weight HA, and synovial fluid viscosity decreased after both synovitis and lavage interventions. Synovial fluid lubricin concentrations increased 17-20-fold for both synovitis and lavage models, with similar changes in both affected and contralateral joints, suggesting that repeated arthrocentesis alone resulted in elevated synovial fluid lubricin concentrations. Synovitis resulted in a more severe inflammatory response based on clinical signs (temperature, heart rate, respiratory rate, lameness and joint effusion) and clinicopathological and biochemical parameters (white blood cell count, total protein, prostaglandin $E_{2}$, sulfated glycosaminoglycans, tumor necrosis factor-a and CC chemokine ligands $-2,-3,-5$ and -11 ) as compared to lavage.

* Correspondence: hlr42@cornell.edu

'Department of Clinical Sciences, College of Veterinary Medicine, Cornell University, Ithaca, NY, USA

Full list of author information is available at the end of the article

(c) The Author(s). 2021 Open Access This article is licensed under a Creative Commons Attribution 4.0 International License, which permits use, sharing, adaptation, distribution and reproduction in any medium or format, as long as you give appropriate credit to the original author(s) and the source, provide a link to the Creative Commons licence, and indicate if changes were made. The images or other third party material in this article are included in the article's Creative Commons licence, unless indicated otherwise in a credit line to the material. If material is not included in the article's Creative Commons licence and your intended use is not permitted by statutory regulation or exceeds the permitted use, you will need to obtain permission directly from the copyright holder. To view a copy of this licence, visit http://creativecommons.org/licenses/by/4.0/. The Creative Commons Public Domain Dedication waiver (http://creativecommons.org/publicdomain/zero/1.0/) applies to the data made available in this article, unless otherwise stated in a credit line to the data. 


\begin{abstract}
(Continued from previous page)
Conclusions: Synovial fluid lubricin increased in response to IL-1 $\beta$ synovitis and joint lavage but also as a result of repeated arthrocentesis. Frequent repeated arthrocentesis is associated with inflammatory changes, including increased sulfated glycosaminoglycan concentrations and decreased hyaluronic acid concentrations. Synovitis results in more significant inflammatory changes than joint lavage. Our data suggests that synovial fluid lubricin, TNF-a, CCL2, CCL3, CCL5, CCL11 and sGAG may be useful biomarkers for synovitis and post-lavage joint inflammation. Caution should be exercised when performing repeated arthrocentesis clinically or in experimental studies due to the inflammatory response and loss of HA and synovial fluid viscosity.
\end{abstract}

Keywords: Repeated arthrocentesis, Lubricin, Hyaluronic acid, Chemokine, Rheology, Lubrication, Osteoarthritis

\section{Background}

Lameness due to joint disease is a major cause of decreased performance and loss of use in horses [1, 2]. Treatment can range from systemic medications and nutraceuticals to intra-articular treatment or arthroscopic evaluation, depending upon the nature and severity of the injury. Treatment with systemic non-steroidal anti-inflammatories and intra-articular therapies, including steroids and lubricants, are mainstays of treatment for synovitis and early osteoarthritis (OA) as these drugs interrupt the inflammatory cascade and provide viscosupplementation [1,3-5]. Biologic therapies, such as platelet rich plasma (PRP) or PRP lysate, are also increasingly being used $[4,6,7]$. Early treatment of synovitis is critical to slow the progression of OA by combating inflammation-induced changes in synovial fluid composition and viscosity. Arthroscopic lavage has been used to treat OA and is commonly used to diagnose and treat intra-articular fracture, cartilage damage or idiopathic synovitis [8-11]. There are few nonterminal equine experimental joint injury models that can be used to evaluate changes in synovial fluid composition and response to therapeutics. Intra-articular lavage and interleukin 1 beta (IL-1 $\beta$ )-induced synovitis are two transient experimental models used to mimic clinical synovitis and study early joint disease in a controlled manner without the requirement for euthanasia.

Arthroscopic lavage decreases inflammatory cytokines, including IL-1 $\beta$ and tumor necrosis factor alpha (TNF$\alpha)$, thereby mitigating synovitis and cartilage degradation in rabbits with experimentally-induced stifle OA [8]. A canine cartilage explant study investigated the effect of irrigation fluid osmolality on chondrocyte death and proteolytic gene expression and found no effect on cell death and a decrease in protease gene expression following exposure to all fluid groups [12]. In an ex vivo bovine stifle joint study, articular cartilage surface friction increased following arthroscopic lavage, and lubricin cartilage immunostaining was reduced as compared to non-lavage controls [13]. In equids, arthroscopic lavage is primarily used for the diagnosis and treatment of joint pathology, including septic arthritis, intra-articular fragment removal and treatment of focal cartilage defects and subchondral bone disease [14]. An in vivo equine study comparing gas and liquid arthroscopy in the tarsocrural joint revealed that prostaglandin $\mathrm{E}_{2}$ $\left(\mathrm{PGE}_{2}\right)$ was increased following both gas distension and intra-articular lavage [15]. This data suggests that, while arthroscopic lavage can be therapeutic by removing harmful cytokines in diseased joints, the lavage itself can incite inflammation in healthy joints.

In the healthy joint, hyaluronic acid (HA) and lubricin/proteoglycan 4 work in concert to decrease friction and surface wear between the articular cartilage surfaces and between articular cartilage and soft tissues of the joint such as menisci, enabling pain free movement [1618]. The glycosylation of synovial fluid lubricin has been shown to differ between osteoarthritic and healthy equine joints, which may lead to decreased lubricating ability in diseased joints [19]. Following arthroscopy of equine middle carpal joints, synovial fluid viscosities and HA concentrations decrease for up to 75 days [20]. Bovine cartilage explants, lubricated with lubricin-deficient synovial fluid from humans with camptodactylyarthropathy-coxa vara-pericarditis syndrome (CACP), an arthritis-like autosomal recessive disorder, reveal increased friction coefficients and increased chondrocyte apoptosis as compared to normal synovial fluid or CACP synovial fluid to which lubricin has been added [21]. These changes lead to cartilage degradation and perpetuation of inflammation, highlighting the importance of lubricin's cartilage lubricating function [12]. To avoid these detrimental cartilage effects, synovial fluid (SF) substitutes have been developed for use in humans in the postoperative period. The use of an intra-articular HA product decreased reported postoperative pain and NSAID usage in a single blind randomized controlled pilot study in partial meniscectomy patients. In addition, this intra-articular HA-based synovial fluid substitute decreased patient-reported pain measures for up to 1 year in a prospective, randomized, double-blinded study following knee arthroscopy and cartilage debridement to treat chronic knee pain [22, 23]. To the authors' knowledge, the effects of joint lavage on SF lubricants have not been previously studied in horses. 
Synovitis is characterized clinically by joint swelling and effusion [24]. Synovitis models are well established in horses, with lipopolysaccharide (LPS) [25-29] and IL$1 \beta$ [30-33] being the most frequently used, and IL-1 $\beta$ induced synovitis considered a more appropriate model for early OA due to the known contribution of IL- $1 \beta$ to OA pathogenesis [32]. In human patients presenting to an emergency room with acute knee joint synovitis, synovial fluid aspirated from synovitis knees had inferior lubrication properties as compared to healthy synovial fluid [34]. In a comparison between inflammatory and non-inflammatory OA SF as defined by a white blood cell count higher than 2000 cells $/ \mathrm{mm}^{3}$, inflammatory SF caused increased tissue strain on cartilage explants, resulting in increased chondrocyte death and apoptosis [35]. Cartilage breakdown products elicit the release of proinflammatory and catabolic mediators from synovial membrane and cartilage, including IL- $1 \beta$, TNF- $\alpha$, matrix metalloproteases (MMPs), and prostaglandin $\mathrm{E}_{2}\left(\mathrm{PGE}_{2}\right)$ and many others which propagate the inflammation and exacerbate joint deterioration [24]. IL-1 $\beta$ and TNF- $\alpha$ have been shown to increase acutely following traumatic injury of the fetlock in Standardbred racehorses and remain elevated for 3 years, while TNF- $\alpha$ was predictive of radiographic progression of fetlock OA [36]. An equine model of amphotericin B-induced synovitis showed a delayed but sustained elevation of IL- $1 \beta$ and TNF- $\alpha$ over the 9-week study period [37].

Chemokines are a large group of molecules that are divided into families based on the relative positions of their cysteine residues [38]. All chemokine receptor ligands recruit immune cells to areas of inflammation, but the CC chemokine receptor ligand family with two adjacent cysteine residues (CCLs) such as CCL2, CCL3, CCL5, and CCL11 mainly act on monocytes and lymphocytes [3942]. Recently developed assays to measure CCL concentrations suggest that these molecules have potential as pro-inflammatory biomarkers based on their presence on stimulated immune cells and their activation of macrophages into pathways that stimulate anti-microbial and tumor activity and promote immunoregulation and tissue healing $[43,44]$. Chemokines are increased in diverse inflammatory diseases $[40,42,45]$ and recruit inflammatory cells to bone and connective tissue in rheumatoid arthritis [45]. In addition to certain subsets of chemokines being reduced in $\mathrm{OA}$ and rheumatoid arthritis compared to healthy synovial fluid while other subsets are elevated in these groups, certain CC chemokines in synovial fluid influence the migration of human mesenchymal cell progenitors which could affect cartilage healing following joint injury [46]. Chemokines have been minimally investigated in equine joint disease to date.

Given the importance of synovial fluid inflammatory biomolecules and lubricants in joint health and $\mathrm{OA}$ progression, our objective was to compare clinical, biochemical and synovial fluid biophysical parameters in the equine IL-1 $\beta$-induced carpal synovitis model and intra-articular tarsocrural lavage model. We hypothesized that lubricin and HA concentrations would decrease in both models and that both models would result in transient, self-limiting joint inflammation associated with measurable increases in pro-inflammatory cytokines/chemokines.

\section{Results}

Six horses ( 3 mares and 3 geldings) from 8 to 20 years of age (mean: 14.5 years, median: 15 years) and weights ranging from 511 to $636 \mathrm{~kg}$ (mean: $570 \mathrm{~kg}$, median: 568.2 $\mathrm{kg}$ ) were included in this study. IL-1 $\beta$-induced synovitis resulted in moderate, transient increases in heart rate (HR) and rectal temperature (T) (synovitis peak HR: $52 \pm 2$ beats per minute at $12 \mathrm{~h}, p=0.0001$; synovitis peak T: $101.1 \pm 0.2^{\circ} \mathrm{F}$ at $12 \mathrm{~h}, p=0.0001$ ), while lavage resulted in a slight increase in rectal temperature at $12 \mathrm{~h}$ (lavage peak T: $99.6 \pm 0.1^{\circ} \mathrm{F}, p=0.001$ ) and no increases in HR (Supplemental Data 1A-D). Respiratory rate (RR) was unchanged post-synovitis and decreased at 6-12 $\mathrm{h}$ post-lavage (lavage trough RR: $12 \pm 2.4$ breaths per minute at $6 \mathrm{~h}, p=0.015$ ) (Supplemental Data 1E-F). Induction of synovitis in the middle carpal joint resulted in an increase in joint circumference (JC) from baseline from 12 to $48 \mathrm{~h}$ and at $1,2,3$, and 4 weeks (synovitis peak JC: 1.1 times baseline at $48 \mathrm{~h}, p=0.0001$ ), and the synovitis $\mathrm{MCJ}$ was increased in circumference from the contralateral MCJ from 12 to $48 \mathrm{~h}$ and at 5 weeks at $48 \mathrm{~h}(p=$ 0.0001). Intra-articular lavage of the tarsocrural joint did not change joint circumference (Supplemental Data 1G$\mathrm{H})$. Synovitis resulted in a severe but temporary lameness on the synovitis limb that returned to baseline by $24 \mathrm{~h}$ post-induction (mean vector sum baseline: $2 \pm 4$, synovitis mean vector sum peak: $105 \pm 7, p=0.001$ ) (Fig. 1a). Horses began the study with a slight predisposition for pushoff lameness on the contralateral hindlimb prior to lavage (negative value) and progressed to soundness (from -2 to +2 ) at $168 \mathrm{~h}$ post lavage (pushoff value baseline: $-3.8 \pm 1$, lavage pushoff peak: $-0.16 \pm 1, p=$ 0.006) (Fig. 1b).

Synovial fluid clinicopathological and biochemical parameters were used to both validate the IL- $1 \beta$ synovitis model and to compare inflammatory changes between the IL- $1 \beta$ synovitis and lavage models (Fig. $1 \mathrm{c}-\mathrm{h}$ and Supplemental Data 2). Total protein (TP) and white blood cell concentration (WBC) increased following induction of both models for $72 \mathrm{~h}$, with a greater magnitude of increase in the synovitis model (peak TP synovitis: $6.5 \pm 0.2 \mathrm{~g} / \mathrm{dL}, p=0.0001$; peak TP lavage: $3 \pm$ $0.3 \mathrm{~g} / \mathrm{dL}, p=0.0001$ ); peak WBC synovitis: $97,200 \pm 26$, 400 cells $/ \mu \mathrm{L}, \mathrm{p}=0.0001$; peak WBC lavage: $11,800 \pm$ 

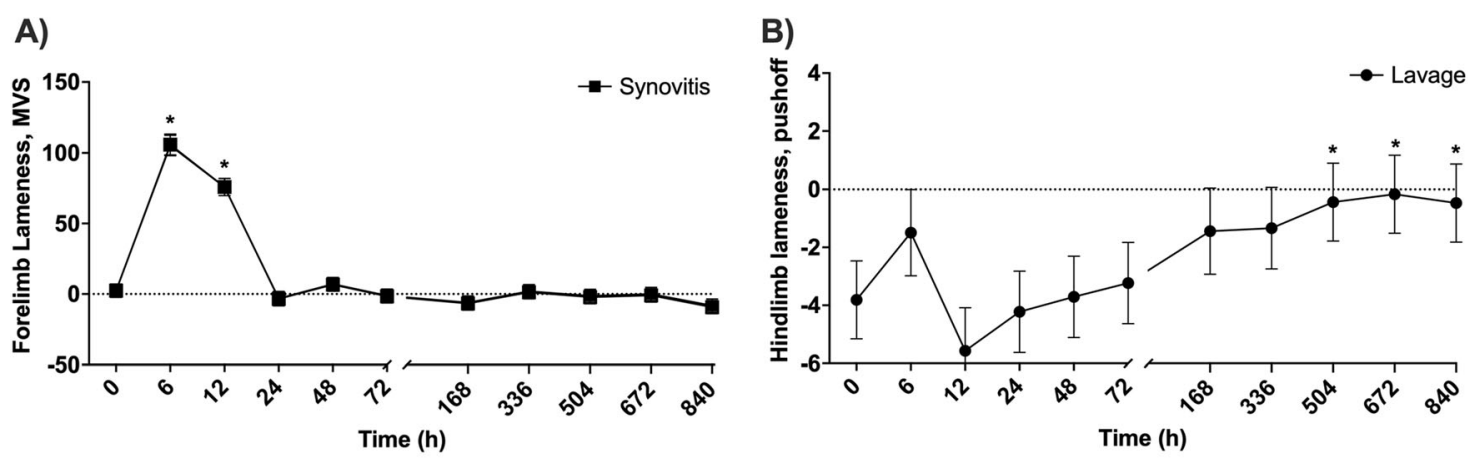

C)

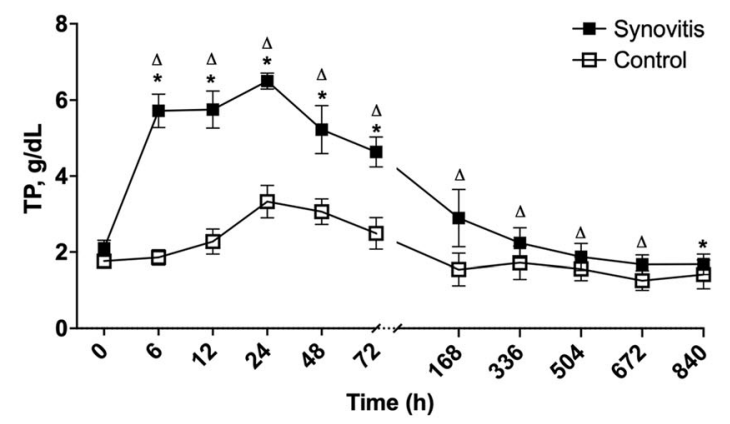

E)

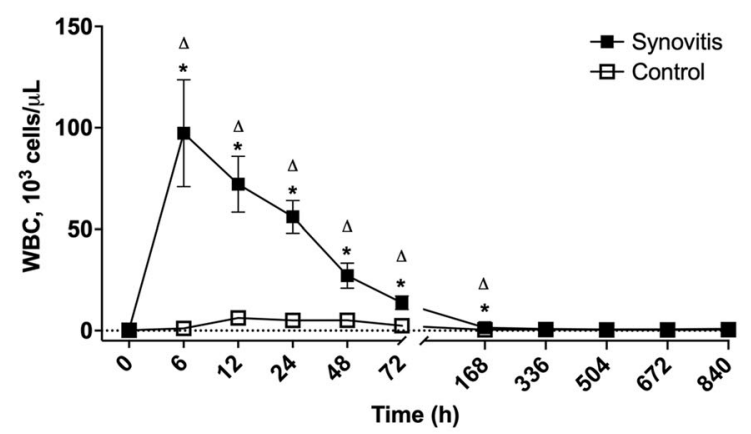

G)

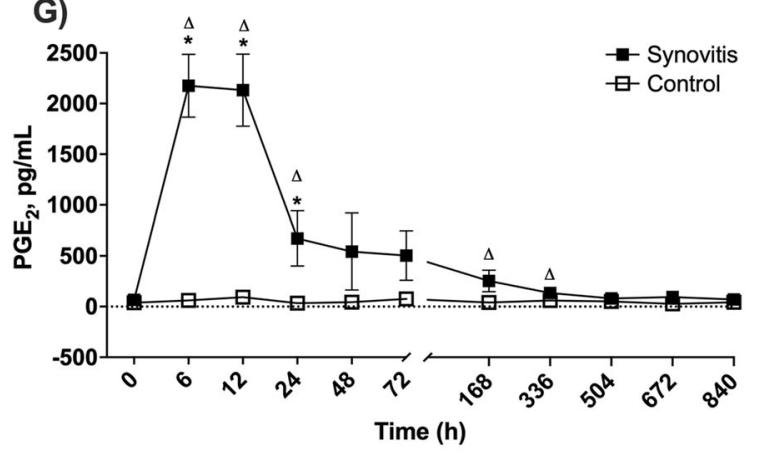

D)

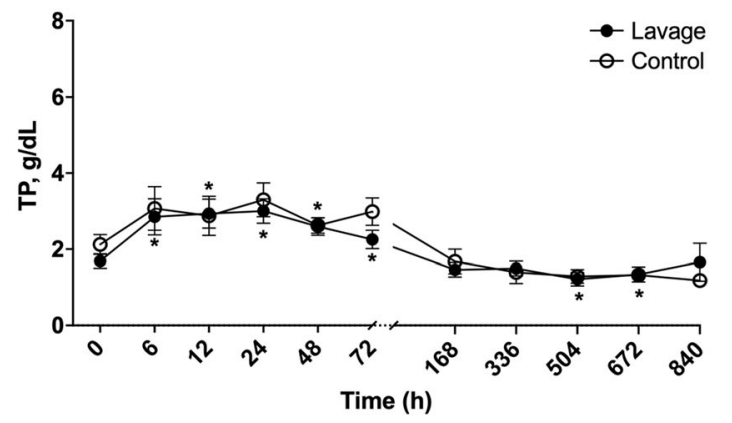

F)

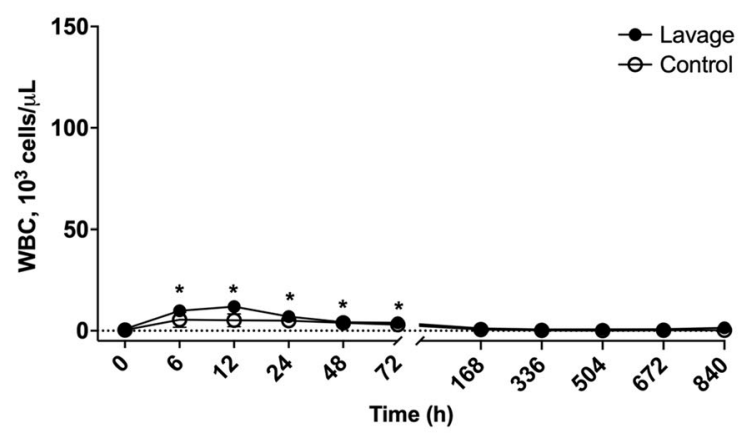

H)

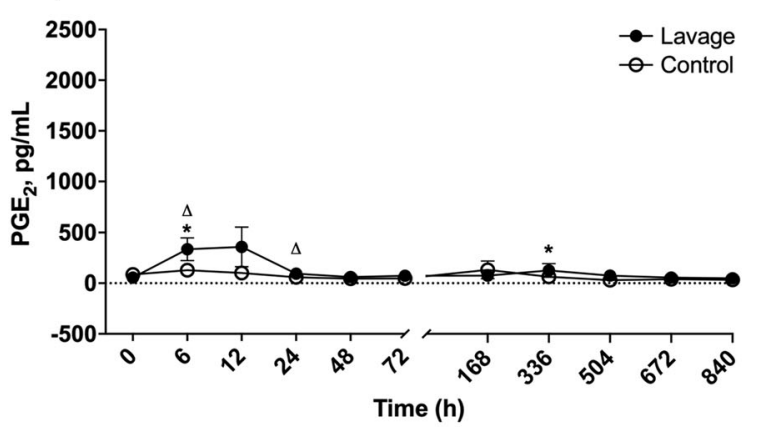

* - Significant difference from baseline

$\Delta$ - Significant difference from contralateral limb

Fig. 1 (See legend on next page.) 
(See figure on previous page.)

Fig. 1 Lameness scores and total protein (TP), white blood cell (WBC), and prostaglandin $E_{2}\left(P_{G} E_{2}\right)$ concentrations in the synovial fluid of middle carpal joints (MCJ) and tarsocrural joints (TCJ) following IL-1 $\beta$-induced synovitis or intra-articular lavage. Forelimb lameness, as measured by mean vector sum using an inertial motion sensor system, increased markedly from baseline for $12 \mathrm{~h}$ post-induction of synovitis on the synovitis limb (a). Hind limb lameness as measured by pushoff factor showed that horses started the study with a trend toward mild lameness of the contralateral hindlimb (negative values) in the first week but became sound $(-2$ to +2$)$ in the last 4 weeks of the study (b). TP increased from baseline for 72 $\mathrm{h}$ following synovitis induction and was greater in synovitis MCJ as compared to contralateral MCJ for 4 weeks post-synovitis induction. TP decreased from baseline at 5 weeks post-induction (c). TP increased from baseline for $72 \mathrm{~h}$ following lavage with no differences from contralateral TCJ. TP decreased from baseline at 3 and 4 weeks post-lavage (d). WBC counts increased from baseline and were greater in synovitis MCJ as compared to contralateral MCJ for 1 week post-synovitis induction (e). WBC counts increased from baseline for $72 \mathrm{~h}$ following lavage with no differences from contralateral TCJ (f). $\mathrm{PGE}_{2}$ increased from baseline for $24 \mathrm{~h}$ following synovitis and was greater in synovitis $\mathrm{MCJ}$ as compared to contralateral MCJ for the majority of 2 weeks post-synovitis induction (g). Following lavage, $\mathrm{PGE}_{2}$ increased from baseline at $6 \mathrm{~h}$ and was greater in lavage TCJ as compared to contralateral TCJ at 6 and $24 \mathrm{~h}$ post-lavage (h). An asterisk indicates a difference from baseline, and a triangle indicates a difference from the contralateral limb at the same time point. Graphed values are marginal means +/- SEM

3000 cells/ $\mu \mathrm{L}, p=0.001$ ) (Fig. 1c-f). Synovitis induction resulted in significant increases in $\mathrm{PGE}_{2}$ from baseline at 6,12 , and $24 \mathrm{~h}$ with differences from the sham-injected control limb at $6,12,24,168$, and $336 \mathrm{~h}$ (synovitis $\mathrm{PGE}_{2}$ baseline: $67 \pm 27 \mathrm{pg} / \mathrm{mL}$; synovitis $\mathrm{PGE}_{2}$ peak: $2176 \pm$ $310 \mathrm{pg} / \mathrm{mL}, p=0.0001)$. Lavage only resulted in slight increases in $\mathrm{PGE}_{2}$ concentration from baseline at 6 and $336 \mathrm{~h}$ post-lavage with differences between lavage and control limbs only detected at 6 and $24 \mathrm{~h}$ post-lavage (lavage $\mathrm{PGE}_{2}$ baseline: $55 \pm 48 \mathrm{pg} / \mathrm{mL}$; lavage $\mathrm{PGE}_{2}$ peak: $335 \pm 112 \mathrm{pg} / \mathrm{mL}, p=0.046)$. The synovitis model $\mathrm{PGE}_{2}$ concentrations were significantly higher than the lavage model at $6,12,24$, and $72 \mathrm{~h}$ post-induction $(p=0.0001)$.

The effects of each model on synovial fluid HA concentration and viscosity were evaluated (Fig. 2 and Supplemental Data 2). Following synovitis, HA concentration decreased from baseline at $6,24,72,168$, 504 , and $840 \mathrm{~h}$ with differences between control and synovitis joints at $336 \mathrm{~h}$ only (synovitis HA baseline: $0.5 \pm 0.1 \mathrm{mg} / \mathrm{mL}$; synovitis HA trough: $0.2 \pm 0.03 \mathrm{mg} / \mathrm{mL}$, $p=0.0001)$. HA concentration also decreased following lavage at $6,12,72,168,336,504$ and $840 \mathrm{~h}$ with differences between control and lavage joints present only at $672 \mathrm{~h}$ (lavage HA baseline: $0.5 \pm 0.1 \mathrm{mg} / \mathrm{mL}$; lavage HA trough: $0.32 \pm 0.05 \mathrm{mg} / \mathrm{mL}, p=0.0001$ ) (Fig. 2a-b). The proportion of high molecular weight $\mathrm{HA}(>6 \mathrm{MDa})$ decreased from baseline from 6 to $168 \mathrm{~h}$ post-induction of synovitis and was decreased from the contralateral limb from 6 to $48 \mathrm{~h}(p=0.0001)$. The lavage model resulted in an increased proportion of high molecular weight HA from baseline at $48,504,672$, and $840 \mathrm{~h}(p=0.001)$. There were no differences in the proportion of high MW HA between intervention and control limbs following lavage (Fig. 2c-d). Viscosity was decreased following induction of synovitis for the duration of the study period and was significantly decreased from the contralateral sham-injected limb at 24, 72, and $672 \mathrm{~h}$ (synovitis viscosity baseline: $85 \pm 20 \mathrm{cP}$; synovitis viscosity trough:
$14 \pm 4 \mathrm{cP}, p=0.002)$. Viscosity remained fairly stable following lavage, with decreased viscosity noted in the lavage limb at $168 \mathrm{~h}$ only, and a decreased viscosity in the lavage joint as compared to the contralateral joint at 72 $\mathrm{h}$ (lavage viscosity baseline: $17 \pm 5 \mathrm{cP}$; lavage viscosity trough $9 \pm 5.5 \mathrm{cP}, p=0.004)$. The middle carpal joint (MCJ) had significantly higher viscosity than the tarsocrural joint (TCJ) at baseline ( $p=0.007)$ (Fig. 2e-f) [47].

The effects of each model on synovial fluid lubricin and sulfated glycosaminoglycan (sGAG) concentrations were evaluated using a sandwich ELISA and dimethylmethylene blue (DMMB) assay, respectively (Fig. 3a-d and Supplemental Data 2). Lubricin increased markedly in all sampled joints regardless of treatment, with infrequent differences between the intervention and control joints (synovitis lubricin baseline: $74 \pm 17 \mu \mathrm{g} / \mathrm{mL}$; synovitis lubricin peak: $1504 \pm 260 \mu \mathrm{g} / \mathrm{mL}, p=0.0001$; lavage lubricin baseline: $77 \pm 27 \mu \mathrm{g} / \mathrm{mL}$; lavage lubricin peak: $1535 \pm 307 \mu \mathrm{g} / \mathrm{mL}, p=0.0001)$ suggesting that repeated arthrocentesis may have been the primary determinant of this response (Fig. 3a-b). Lubricin concentrations peaked at $48 \mathrm{~h}$ post-induction for both models and decreased as the arthrocentesis intervals increased from 1 week on. Sulfated glycosaminoglycan concentration increased in response to both models, albeit to a greater extent in synovitis (Fig. 3c-d). Following induction of synovitis, the sGAG concentration remained elevated from 6 to $72 \mathrm{~h}$ post-induction, with significant differences from the sham-injected joint at 12, 24, 48, 72 and $840 \mathrm{~h}$ (synovitis sGAG baseline: $385 \pm 23 \mu \mathrm{g} / \mathrm{mL}$; synovitis sGAG peak: $711 \pm 24 \mu \mathrm{g} / \mathrm{mL}, p=0.0001)$. The lavage model resulted in an increase in sGAG concentration from 24 to $72 \mathrm{~h}$ post-lavage and a decrease in concentration from baseline at 504 and $672 \mathrm{~h}$ post-lavage with no differences between lavage and control joints (lavage sGAG baseline: $276 \pm 9 \mu \mathrm{g} / \mathrm{mL}$; lavage sGAG peak: $418 \pm 48 \mu \mathrm{g} / \mathrm{mL}, p=0.002)$. The MCJ had an increased concentration of sGAG as compared to the 


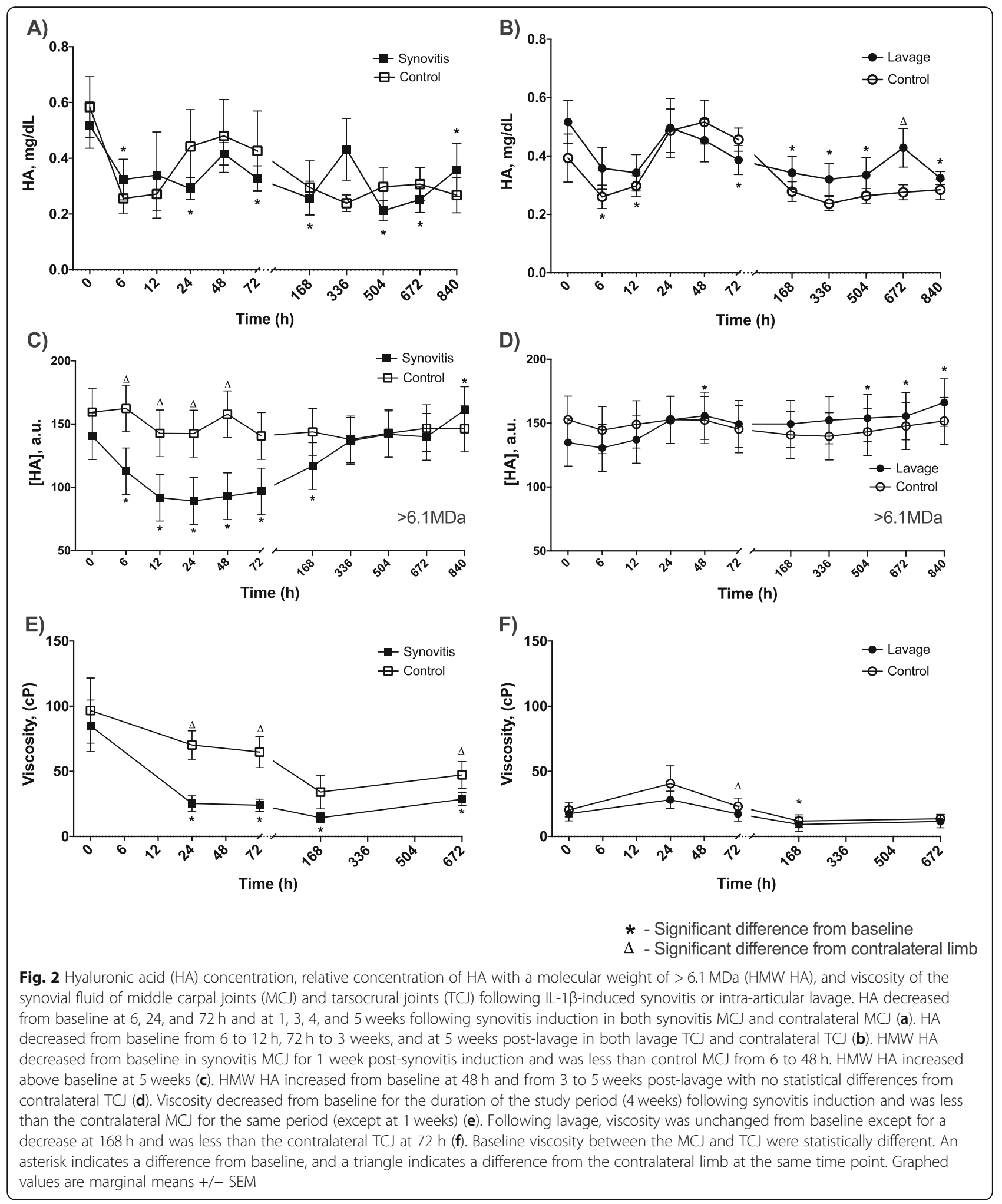

TCJ at baseline ( $p=0.0001)$, and the sGAG concentration remained elevated in the MCJ compared to the TCJ for the entire study period.
A fluorescent bead-based multiplex assay was performed to assess synovial fluid inflammatory cytokine and chemokine changes induced by each model 


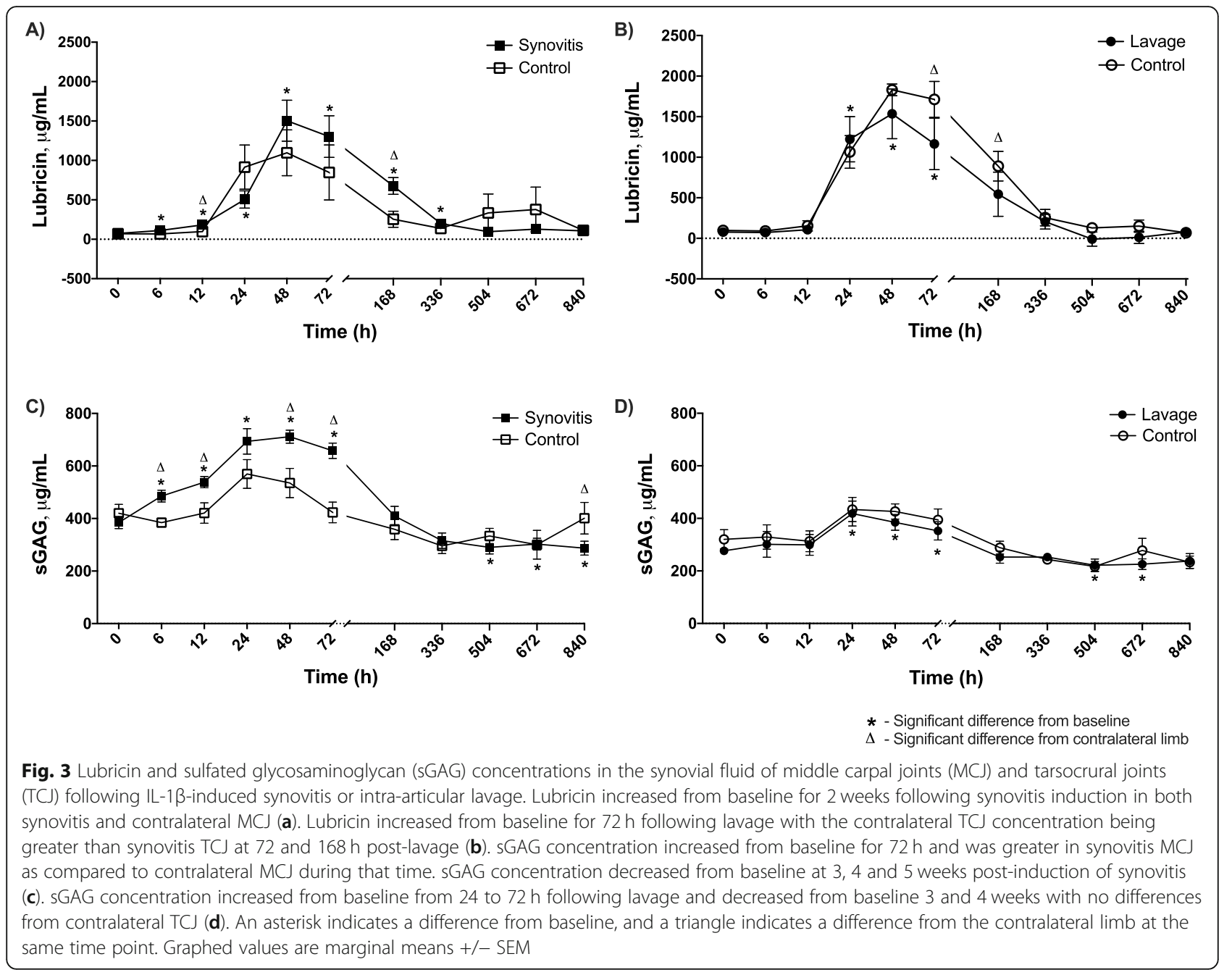

(Figs. 4a-b and 5a-h and Supplemental Data 2). IL-1 $\beta$ concentration did not vary from baseline or between the control and affected joint following induction of either model, although a non-significant peak was present at 6 $\mathrm{h}$ post-induction of both synovitis and lavage (synovitis IL-1 $\beta$ baseline: $715 \pm 620 \mathrm{pg} / \mathrm{mL}$; synovitis IL-1 $\beta$ peak: $2536 \pm 2004 \mathrm{pg} / \mathrm{mL}$ at $6 \mathrm{~h}$; lavage IL-1 $\beta$ baseline: $286 \pm$ $269 \mathrm{pg} / \mathrm{mL}$; lavage IL-1 $\beta$ peak: $1001 \pm 888 \mathrm{pg} / \mathrm{mL}$ ) (Fig. 4a-b). TNF- $\alpha$ concentration increased from baseline at $6 \mathrm{~h}$ post-induction of synovitis and was greater than the contralateral sham-injected $\mathrm{MCJ}$ at $6 \mathrm{~h}$ postinduction (synovitis TNF- $\alpha$ baseline: $-6 \pm 421 \mathrm{pg} / \mathrm{mL}$; synovitis TNF- $\alpha$ peak: $4276 \pm 421 \mathrm{pg} / \mathrm{mL}, p=0.0001$; lavage TNF- $\alpha$ baseline: $-10 \pm 421 \mathrm{pg} / \mathrm{mL}$; lavage TNF- $\alpha$ peak: $49 \pm 421 \mathrm{pg} / \mathrm{mL}$ ) (Fig. $4 \mathrm{c}$ ). TNF- $\alpha$ was not altered by intra-articular lavage (Fig. 4d). An increase in CCL2 concentration was seen at 6,12 , and $24 \mathrm{~h}$ post-induction of synovitis with differences from the contralateral limb at 6 and $24 \mathrm{~h}$. Following lavage, CCL2 was increased from baseline at 6 and $12 \mathrm{~h}$ (synovitis CCL2 baseline: $146 \pm 8337 \mathrm{pg} / \mathrm{mL}$; synovitis CCL2 peak: 93,869 \pm 8335 $\mathrm{pg} / \mathrm{mL}, p=0.0001$; lavage CCL2 baseline: $-123 \pm 8337$ $\mathrm{pg} / \mathrm{mL}$; lavage CCL2 peak: 37,993 $\pm 8335 \mathrm{pg} / \mathrm{mL}, p=$ 0.001) (Fig. 5a-b). An increase in CCL3 concentration from baseline was seen at $6 \mathrm{~h}$ post-induction of synovitis, with an increase in CCL3 in the synovitis as compared to control MCJ at $6 \mathrm{~h}$ (synovitis CCL3 baseline: $59 \pm 330$ $\mathrm{pg} / \mathrm{mL}$; synovitis CCL3 peak: $2209.5 \pm 330 \mathrm{pg} / \mathrm{mL}(p=$ $0.0001)$ ) (Fig. 5c). There were no differences from baseline or control limb in CCL3 concentration post-lavage; however, CCL3 concentrations were greater in control as compared to lavage TCJ at baseline (lavage CCL3 baseline: $-8 \pm 330 \mathrm{pg} / \mathrm{mL}$; lavage CCL3 peak: $183 \pm 331$ $\mathrm{pg} / \mathrm{mL}$ ) (Fig. $5 \mathrm{c}-\mathrm{d}$ ). Following synovitis, CCL5 concentrations were increased from baseline at 6,12 , and $72 \mathrm{~h}$ and were greater in the synovitis joint as compared to the contralateral MCJ at 6,72 , and $168 \mathrm{~h}$ (synovitis CCL5 baseline: $167 \pm 160 \mathrm{pg} / \mathrm{mL}$; synovitis CCL5 peak: $634 \pm$ $159 \mathrm{pg} / \mathrm{mL}, p=0.0001$ ) (Fig. 5e). CCL5 concentrations were not altered by intra-articular lavage (lavage CCL5 baseline: $99 \pm 160 \mathrm{pg} / \mathrm{mL}$; lavage CCL5 peak: $200 \pm 160$ $\mathrm{pg} / \mathrm{mL}$ ) (Fig. 5f). CCL11 was increased from baseline at 


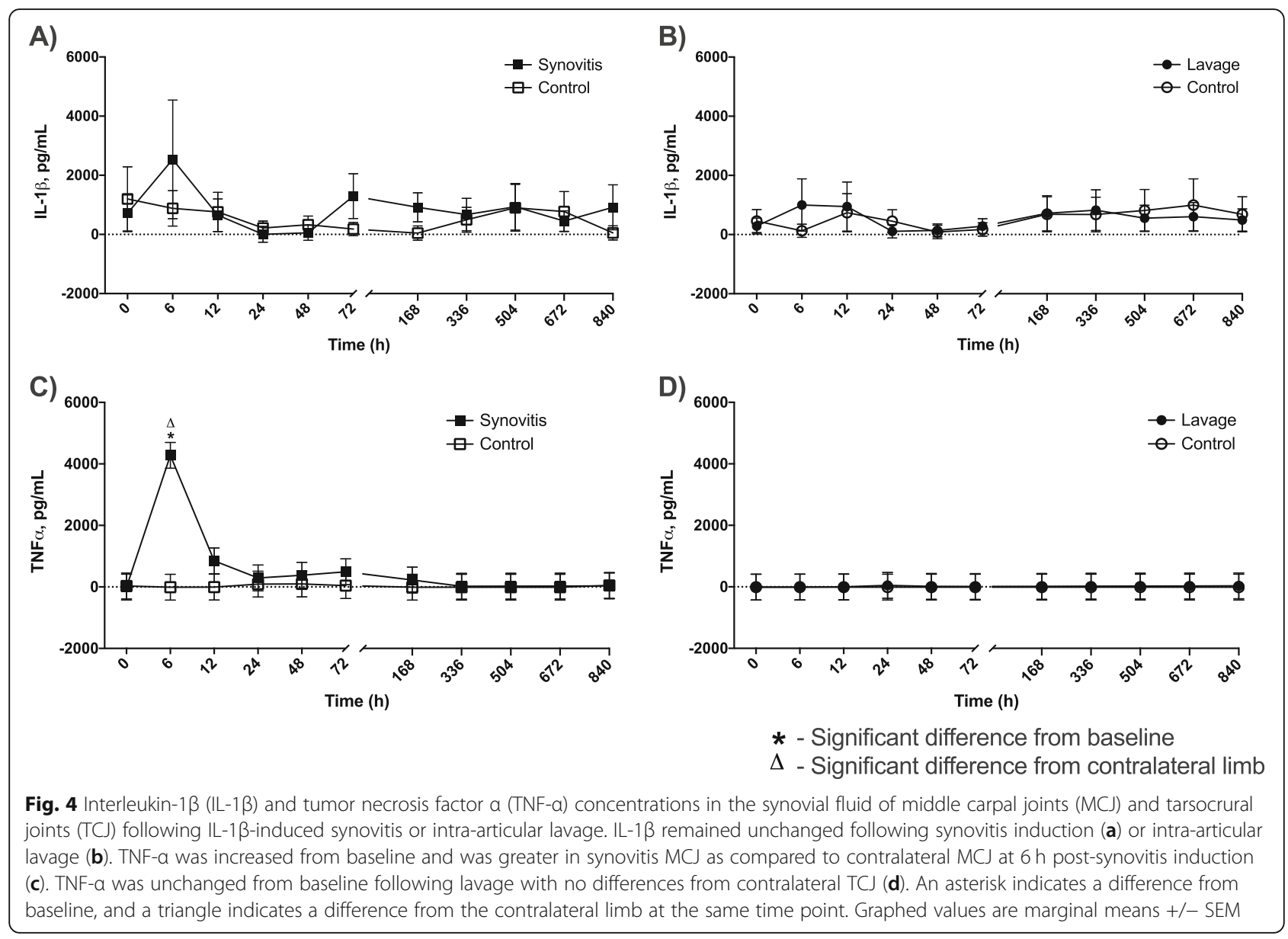

6-72 $\mathrm{h}$ post-synovitis and at 6 and $12 \mathrm{~h}$ post-lavage (synovitis CCL11 baseline: $3288 \pm 2521 \mathrm{pg} / \mathrm{mL}$; synovitis CCL11 peak: $16,225 \pm 2520 \mathrm{pg} / \mathrm{mL}, p=0.0001$; lavage CCL11 baseline: $1951 \pm 2521 \mathrm{pg} / \mathrm{mL}$; lavage CCL11 peak: $9883 \pm 2520 \mathrm{pg} / \mathrm{mL}, p=0.002$ ) (Fig. $5 \mathrm{~g}-\mathrm{h}$ ). CCL11 concentration was greater in the synovitis MCJ than the contralateral MCJ at 6-48 h $(p=0.0001)$, and there were no differences between limbs following lavage.

In order to assess inflammatory gene expression and expression of the genes encoding for hyaluronic acid synthases (HAS1, HAS2, HAS3), lubricin (proteoglycan 4, PRG4), TNF- $\alpha$ stimulated gene 6 (TSG6) and IL-1 $\beta$ $(I L 1 \beta)$, quantitative RT-PCR analysis of synovial fluid cell pellets was performed at 12 and $24 \mathrm{~h}$ postinduction of synovitis or lavage and of synovial membrane biopsies at 5 weeks post-induction of synovitis or lavage. Genes and primer sequences are available in Supplemental Data 3. TSG6 expression was increased in synovial fluid cell pellets from the synovitis MCJ as compared to the lavage TCJ at $12 \mathrm{~h}$ and $24 \mathrm{~h}$ postinduction $(p=0.0001)$. At $24 \mathrm{~h}$ post-induction, TSG6 expression was greater in the synovitis MCJ than the contralateral, sham-injected MCJ $(p=0.013)$. At $12 \mathrm{~h}$ post-induction of synovitis, both HA synthase 1 (HAS1) $(p=0.024)$ and HA synthase $3(H A S 3)(p=0.01)$ expression were decreased in the cell pellets of the synovitis $\mathrm{MCJ}$ as compared to the lavage TCJ. There were no differences between groups in synovial fluid cell pellet PRG4 expression. In the synovial membrane samples, there were no differences between groups in $H A S 2$, IL$1 \beta$ or PRG4 expression. There were no histological differences in vascularity, inflammatory cellular infiltration, intimal hyperplasia, subintimal edema, and subintimal fibrosis between synovitis and lavage or between intervention and control limbs.

\section{Discussion}

Both IL-1 $\beta$-induced synovitis and intra-articular lavage resulted in transient joint inflammation with elevations in synovial fluid $\mathrm{TP}, \mathrm{WBC}$ count, and $\mathrm{PGE}_{2}$; however, increases in TNF- $\alpha$ and inflammatory chemokines CCL2, CCL3, CCL5, and CCL11 were predominantly restricted to synovitis joints only. Synovial fluid sGAG and lubricin increased significantly in both intervention and control joints in both synovitis and lavage models, accompanied by a loss of HA, especially high MW HA, in 


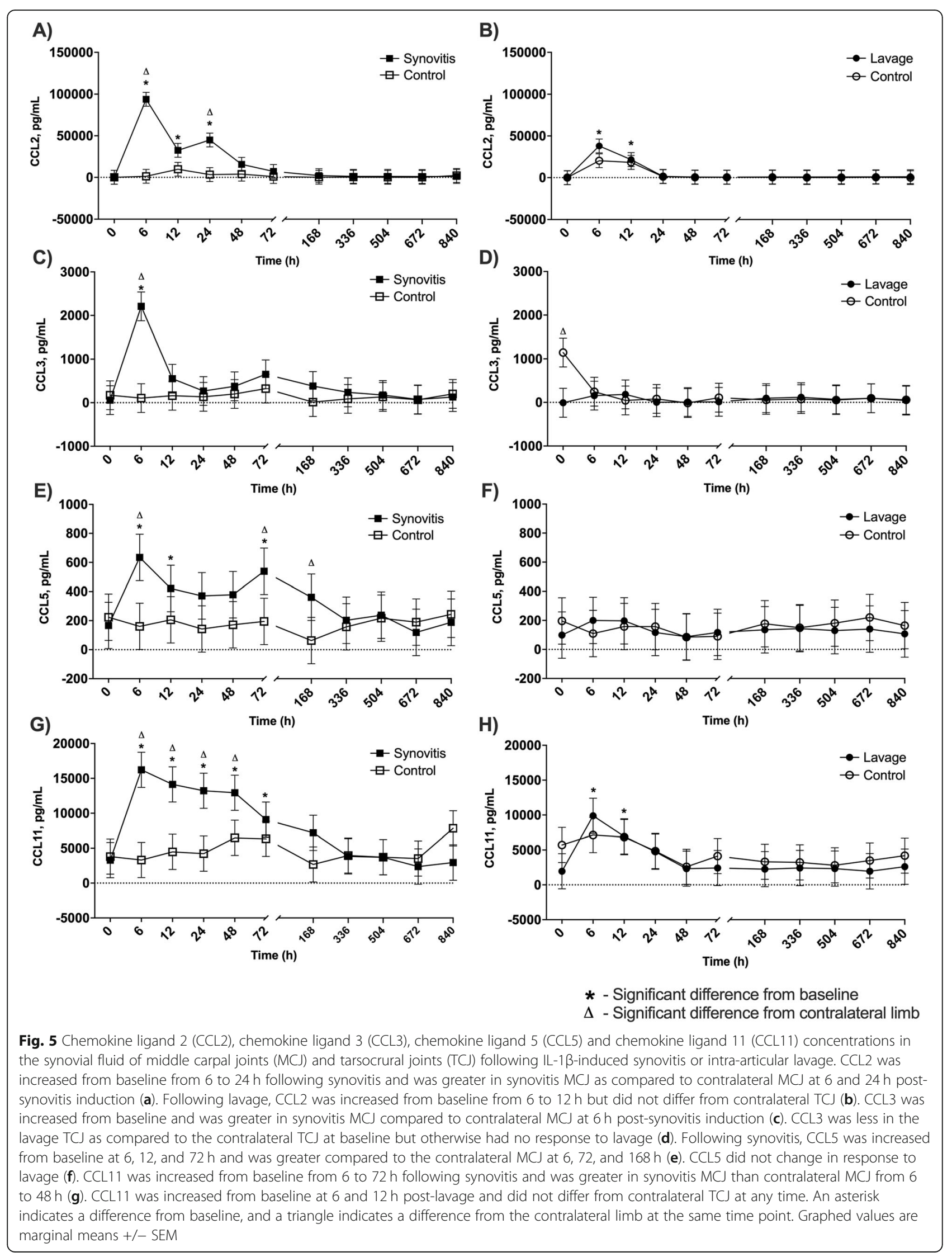


both intervention and control joints. Likewise, synovial fluid viscosity decreased in both intervention and control joints, albeit to a greater extent in synovitis than lavage joints. This is the first report to demonstrate an increase in synovial fluid lubricin following either IL-1 $\beta$-induced synovitis or intra-articular lavage, contrary to our hypotheses. The inflammatory changes observed suggest that both models induce transient inflammation, more pronounced in the synovitis model, and that either a systemic effect, or more likely repeated arthrocentesis may contribute to inflammation and changes in lubricating molecules in both the intervention and control joints.

Increased synovial fluid lubricin has been observed in several experimental and naturally occurring equine models of joint disease, including carpal osteochondral fragmentation, tarsal impact injury, full-thickness cartilage defect injury and spontaneous osteochondral fragmentation and osteoarthritis [47-49]. Interestingly, in prior studies investigating the equine carpal osteochondral fragment high-speed treadmill exercise model, synovial fluid lubricin concentrations were increased in both the fracture joint and, to a lesser extent, in the sham-operated control joint, possibly due to compensatory overloading of the control limb [20, 48]. Results from the current study may be able to help account for the findings in the sham-operated control joint, as these carpi undergo lavage during the arthroscopic shamoperation and are subjected to repeated arthrocentesis at weekly or more frequent intervals. LPS-induced equine synovitis models have shown decreased HA over a $48 \mathrm{~h}$ period, and a quantitative intercompartmental synovial joint model predicted that HA would take longer to reach a steady state concentration than lubricin following intra-articular lavage [50-52].

While intra-articular lavage resulted in loss of HA, either due to synovial fluid washout, increased degradation, or decreased production, it was surprising that lavage resulted in an increase in synovial fluid lubricin given prior in vitro data in bovine cartilage explants [13]. We hypothesized that intra-articular lavage would result in synovial fluid washout due to removal of synovial fluid from the joint, at least in the early post-lavage period. Unexpectedly, lubricin increased as early as $24 \mathrm{~h}$ post-lavage, peaking at $48 \mathrm{~h}$ post-lavage. The stimulus responsible for increased synovial fluid lubricin in these models is poorly understood and requires further exploration. One theory is that lubricin-coated white blood cells, such as peripheral mononuclear cells (PMNs), may contribute to the measured increases in synovial fluid lubricin by localizing to inflamed synovial fluid and joint tissues [53]. This theory would link the early increase in inflammatory cell-recruiting chemokines with the slightly delayed increase in lubricin in both intervention and control joints. However, the possibility of increased synovial membrane capillary permeability causing leakage of lubricin from the bloodstream, hemarthrosis as a result of arthrocentesis, and release from cartilage due to increased concentration of cartilage matrix degrading enzymes such as elastase [54, 55] cannot be ruled out based on the results of this study. Even so, this data suggests that lubricin may be a sensitive biomarker for joint inflammation.

IL-1 $\beta$ was chosen for the induction of synovitis as it induces a similar level of inflammation to equine synovial fluid as LPS and is a known contributor to the etiology of arthritis [32]. The absent response in IL-1 $\beta$ concentration and the brief TNF- $\alpha$ increase observed in IL-1 $\beta$-induced synovitis joints differ from previous findings in the amphotericin B-induced synovitis model [37], which showed a sustained increase in concentration of these cytokines in synovial fluid for 9 weeks. Synovial fluid IL-1 $\beta$ protein concentrations have also been shown to increase in horses $8 \mathrm{~h}$ after LPS-induced synovitis [56] and in horses with naturally occurring OA [57]. The multiplex assay used in this study is capable of detecting $E$. coli-produced recombinant equine IL-1 $\beta$. While there were no significant differences, there was a nonsignificant peak in IL-1 $\beta$ at $6 \mathrm{~h}$ post-induction of synovitis, which was likely residual recombinant IL- $1 \beta$ from the injection. Our data suggests that recombinant equine IL- $1 \beta$ is not auto-inductive despite resulting in significant elevations in TNF- $\alpha$, CCL2, CCL3, CCL5, and CCL11. Increased IL-1 $\beta$ gene expression in synovium and articular cartilage has previously been reported in an equine IL-1 $\beta$-induced synovitis model [58] and in naturally occurring osteoarthritis [59]; however, IL-1 $\beta$ gene expression does not necessarily correlate with bioactive IL-1 $\beta$ due to the requirement for posttranslational modifications such as protease cleavage to result in the secreted, bioactive form of IL-1 $\beta$ [60]. Our sampling timeline for gene expression at day 30 may have missed the critical window to capture changes in IL- $1 \beta$ gene expression.

The synovial fluid chemokine results demonstrate the value of these inflammatory molecules as biomarkers following joint trauma. All 4 chemokine ligands rapidly increased by $6 \mathrm{~h}$ post induction of synovitis with no change in the contralateral MCJ, suggesting that repeated arthrocentesis alone did not induce these ligands. CCL2 and CCL11 showed mild increases in concentration in response to the lavage model that were not different from the contralateral TCJ. Whereas CCL2 and CCL3 returned to baseline levels within $24 \mathrm{~h}$, CCL5 and CCL11 remained elevated from baseline for $72 \mathrm{~h}$ in the synovitis model. The data suggest that TNF- $\alpha$, CCL2, CCL3, CCL5, and CCL11 are sensitive markers during early joint inflammation with variations in their temporal responses. 
Repeated arthrocentesis is necessary for studies designed to measure changes in synovial fluid constituents over time and has been employed in nearly all studies evaluating IL-1 $\beta$ or LPS-induced synovitis in horse [32, $36,37,50,52]$. However, arthrocentesis is not an innocuous procedure and can lead to contamination of the joint with hair and debris, in addition to hemorrhage and trauma to the cartilage and synovium [61]. Increased joint circumference has been reported following 4 repeated arthrocenteses over a $24 \mathrm{~h}$ period in horses [62]. Several changes to synovial fluid composition have been documented following a single arthrocentesis in healthy equine and bovine joints, including elevations in matrix metalloproteinase 1 , nitric oxide, $\mathrm{PGE}_{2}$, GAG [63, 64], and increased total leukocyte count [65]. In a previous study, HA content and synovial fluid viscosity as measured by the falling ball technique in equine middle carpal joints decreased following four repeated arthrocenteses over the course of $48 \mathrm{~h}$ [66]. Based on these findings, a sampling time of weekly or less frequently is ideal to prevent repeated arthrocentesis from affecting clinicopathologic outcome measures [63, 67]. However, synovitis models are transient, with most studies only measuring synovial fluid parameters over a $48 \mathrm{~h}$ time period, thereby necessitating more frequent sampling. Therefore, a larger number of study subjects sampled at less frequent intervals may be necessary to reduce the confounding effects of repeated sampling.

Synovial membrane biopsies were obtained at day 35 following induction of synovitis or joint lavage so that synovial fluid inflammatory and lubricating molecules could be studied without contaminating the joints with hemorrhage during the biopsy collection. While this study design was necessary to achieve the primary objectives of the study, 35 days is likely too late to capture the changes in synovial membrane morphology or gene expression induced by these transient models. Addition of more study subjects reserved for biopsy alone at earlier time points would be valuable to capture changes in gene expression and histologic changes. Interestingly, gene expression from synovial fluid cell pellets showed an increase in tumor necrosis factor-inducible gene-6 protein (TSG6) at 12- and 24-h post-induction of synovitis as compared to the lavage TCJ and increased expression at $24 \mathrm{~h}$ as compared to the control MCJ. TSG-6 is a protein with both anti- and pro-inflammatory effects, and its expression is induced by TNF- $\alpha$ [68]. Decreased expression of the hyaluronic acid synthases 1 and 3 in the synovitis MCJ compared to the lavage TCJ at $12 \mathrm{~h}$ post-induction suggesting a possible mechanism for the decreased HA concentration seen in this study, though HAS2 is thought to be the primary contributor to synovial fluid HA expression [69].

An additional limitation to this study is that differences in baseline concentrations of hyaluronic acid in synovial fluid and viscosity exist between the MCJ and the TCJ which complicates the comparison between the synovitis and lavage models [47]; however, the TCJ is ideal for standing lavage and biopsy, and the use of both carpi and both tarsi enabled a randomized, crossover study design that required fewer horses. The multiplex assay used to test synovial fluid for inflammatory cytokines and chemokines is a new assay, and this is the first publication to describe the use of this assay on equine synovial fluid. While this limits the ability to directly compare to other studies, this assay enables assessment of 6 cytokines/chemokines simultaneously, maximizing valuable synovial fluid aliquots, and enables investigation into new potential biomarkers of joint disease and inflammation.

Additional studies are needed to elucidate the molecular mechanisms responsible for the increase in synovial fluid lubricin following repeated arthrocentesis. It is unclear whether synovial fluid lubricin is increased as a result of increased proteoglycan 4 expression in joint tissues, increased expression or release of lubricin from inflammatory WBCs or intra-articular hemorrhage, loss of lubricin from the articular cartilage surface or synovial lining, decreased metabolism/ degradation of lubricin, or a combination of all of these mechanisms. One theory is that lubricin is released or upregulated as a protective mechanism for the joint in the face of inflammation and HA deficiency. In this way, lubricin may allow for continued joint lubrication, anti-adhesion and chondroprotection in situations when $\mathrm{HA}$ is decreased. Equine IL- $1 \beta$ synovitis and intra-articular lavage models are both non-terminal, transient models in which both inflammatory and lubricating molecules have been characterized and which may be valuable for investigations of anti-inflammatory and lubrication supplementation therapies.

\section{Conclusion}

Contrary to previous in vitro reports, synovial fluid lubricin increases in response to IL- $1 \beta$-induced synovitis and joint lavage in vivo. Both synovitis and lavage models induced changes in inflammatory and lubricating molecules, but the inflammatory changes were more pronounced in synovitis joints. Our data suggest that synovial fluid lubricin, in addition to a panel of synovial fluid biomarkers, including TNF- $\alpha$, CCL2, CCL11 and sGAG, may have potential for elucidating the progression of early joint inflammation. Caution should be exercised when performing repeated arthrocentesis at frequent intervals, for either experimental research or clinical cases, due to the inflammatory response and loss of HA and synovial fluid viscosity associated with arthrocentesis. 


\section{Methods}

\section{Experimental design and sampling}

Six horses, free from pathology affecting the middle carpal or tarsocrural joints, were enrolled in a complete block, randomized crossover study design. The experiment was designed to compare the clinical and synovial fluid biochemical and biophysical changes in response to IL-1 $\beta$ induced synovitis in the middle carpal joint (MCJ) and intra-articular lavage in the tarsocrural joint (TCJ). Breeds included Thoroughbred (2), Mustang/Arabian (2), and Warmblood (2), with ages ranging from 8 to 20 years (mean: 14.5 years, median: 15 years) and weights ranging from 511 to $636 \mathrm{~kg}$ (mean: $570 \mathrm{~kg}$, median: $568.2 \mathrm{~kg}$ ). An equal number of mares and geldings were included. Lameness and physical examinations were conducted prior to the study by two veterinarians to ensure that horses had an AAEP lameness grade of 2/5 or less, and carpal and tarsal radiographs were obtained to rule out any pre-existing joint pathology. Three of the horses had no lameness, two horses had a grade 1/5 lameness, and one horse had a grade 2/5 lameness. The horses all had minimal to no joint effusion in the MCJ or TCJ prior to commencement of the study. Treatment limbs were randomized using a Microsoft Excel random number generator with $\mathrm{MCJ}$ and TCJ groups being independent from each other. All horses received IL-1 $\beta$ induced synovitis in the MCJ first, followed by a washout period and the TCJ intra-articular lavage.

One hundred nanograms of recombinant equine IL-1 $\beta$ in $1 \mathrm{~mL}$ phosphate buffered saline (PBS) was administered into one randomly assigned middle carpal joint $(\mathrm{MCJ})$, and the contralateral MCJ was injected with 1 $\mathrm{mL}$ PBS as a sham/vehicle injection. The recombinant equine IL-1 $\beta$ was all from the same lot number and was aliquoted on arrival to limit freeze thaw cycles. Synovial fluid (SF) and blood were collected at 0, 6, 12, 24, 48, 72, 168 (1 week), 336 ( 2 weeks), 504 (3 weeks), 672 (4 weeks), and 840 (5 weeks) hours post-induction of synovitis. At each time point, $3 \mathrm{~mL}$ of synovial fluid was collected, except the $840 \mathrm{~h}$ timepoint when as much fluid as possible was obtained. Following the last collection time point, a synovial membrane biopsy of the MCJ was performed under standing sedation using a small arthrotomy in the dorsolateral aspect of the MCJ and Ferris-Smith rongeurs. These incisions were closed in one layer of nonabsorbable simple, interrupted sutures and were kept bandaged for 3 days following suture removal at day 14 post-procedure.

Following a 30-day wash-out period, which consisted of stall rest or small paddock turn-out, the same six horses entered the second stage of the study. This consisted of an intra-articular lavage performed under standing sedation via placement of four $14 \mathrm{~g}$ needles into each of the four quadrants of the tarsocrural joint
(TCJ)-dorsomedial, dorsolateral, plantaromedial and plantarolateral. Lavage was performed using $2 \mathrm{~L}$ of Lactated Ringer's Solution (LRS) into a randomly selected TCJ. The contralateral limb received no intervention. Synovial fluid and blood were collected over a 35-day period at the same time intervals as described for the synovitis intervention. Following the final collection timepoint at $840 \mathrm{~h}$ (5 weeks), a standing synovial membrane biopsy of the TCJ was obtained in four horses, while two horses were euthanized and samples were collected immediately post-mortem. Synovial fluid and blood were obtained ante-mortem.

All work was conducted under approval by the Institutional Animal Care and Use Committee (2018-0024). All joints were clipped and aseptically prepared prior to administration of recombinant IL- $1 \beta$ or intra-articular lavage, and synovial fluid sampling was performed using aseptic technique. One horse required general anesthesia for the intra-articular lavage due to intractable behavior.

\section{Evaluation of clinical response to treatment}

A physical examination including heart rate, respiratory rate, rectal temperature, joint circumference, and range of motion, was performed at 0, 6, 12, 24, 48, 72, 168 (1 week), 336 ( 2 weeks), 504 (3 weeks), 672 (4 weeks), and 840 ( 5 weeks) hours post-induction of synovitis and lavage. A lameness examination at the walk and trot was performed at each time point, with a veterinarian assessing lameness at the walk and trot and an inertial sensor-based system (Equinosis Q) evaluating gait symmetry at the trot in hand on a firm, synthetic surface. For the synovitis model, bilateral carpal flexions were performed. No flexions were performed for the lavage model.

Joint circumference was measured with a tape measure at three locations for both carpi and tarsi, and the three measurements were averaged to obtain a single measure of effusion/edema. For the MCJ, circumference was measured at the accessory carpal bone $(\mathrm{ACB}), 2 \mathrm{~cm}$ distal to the ACB, and $4 \mathrm{~cm}$ distal to the ACB. For the TCJ, circumference was measured at the medial malleolus of the tibia, $1 \mathrm{~cm}$ distal to the malleolus, and $4 \mathrm{~cm}$ distal to the malleolus.

\section{Sample analysis}

Synovial fluid was sampled/obtained prior to treatment (0 h), 6, 12, 24, 48, 72, 168 (1 week), 336 (2 weeks), 504 ( 3 weeks), 672 ( 4 weeks), and 840 ( 5 weeks) hours postinduction of synovitis or lavage. Arthrocentesis of $3 \mathrm{~mL}$ synovial fluid from either the MCJ or TCJ was performed aseptically following clinical assessment and lameness examination. Horses were sedated using either xylazine $(0.2-0.4 \mathrm{mg} / \mathrm{kg}$ IV) or detomidine hydrochloride $(0.004-0.016 \mathrm{mg} / \mathrm{kg}$ IV) combined with acepromazine 
maleate injection $(0.1-0.2 \mathrm{mg} / \mathrm{kg}$ IV) and butorphanol tartrate $(0.004-0.016 \mathrm{mg} / \mathrm{kg} \mathrm{IV})$. One horse required sedation with morphine sulfate $(0.08-0.2 \mathrm{mg} / \mathrm{kg}$ IV) rather than butorphanol. Synovial fluid was placed in 15$\mathrm{mL}$ conical polypropylene vials on ice and processed within $2 \mathrm{~h}$ of collection. A portion of the aspirate was used for analysis of total nucleated cell count and differential lymphocyte, monocyte, and neutrophil counts using an automated cell counter.

The remainder of the aspirate was centrifuged at 4000 $\mathrm{x} \mathrm{g}$ for $15 \mathrm{~min}$ to remove cells and debris. The synovial fluid supernatants were aliquoted and stored at $-80^{\circ} \mathrm{C}$ in $1.5 \mathrm{~mL}$ Eppendorf tubes. The cell pellet was resuspended in $500 \mu \mathrm{L}$ TRIzol Reagent and stored at $80^{\circ} \mathrm{C}$. Jugular vein blood was collected into glass Vacutainer blood tubes with and without EDTA and centrifuged as above. Serum and plasma were aliquoted into 2 $\mathrm{mL}$ Eppendorf tubes and stored at $-80^{\circ} \mathrm{C}$. From the EDTA tubes, the buffy coat was aspirated from the red blood cell pellet and resuspended in $500 \mu \mathrm{L}$ TRIzol Reagent and stored at $-80^{\circ} \mathrm{C}$. Once all SF samples were collected, they were assessed and scored subjectively for color/hemorrhage.

\section{BCA assay}

A plate-based bicinchoninic acid assay (BCA, ThermoFisher Scientific, Waltham, MA) was performed to measure synovial fluid total protein concentrations colorimetrically [70]. Synovial fluid samples diluted in phosphate buffered saline (1:40 dilution) and a series of bovine serum albumin standards were loaded into a 96 well plate (Corning, Corning, NY) and incubated with BCA Working Reagent for $1 \mathrm{~h}$ at room temperature. Absorbance was measured on a plate reader at $562 \mathrm{~nm}$ (Tecan, Morrisville, NC).

\section{Synovial fluid lubricin (sandwich ELISA)}

Synovial fluid lubricin concentration was measured at all time points by a sandwich ELISA using anti-lubricin monoclonal antibody 9G3 (MABT401; EMD Millipore, Darmstadt) and peanut agglutinin (PNA) (Sigma Aldrich, St. Louis, MO) as previously described [48, 71]. Briefly, after $12 \mathrm{~h}$ of coating at $4{ }^{\circ} \mathrm{C}$ with $10 \mathrm{mg} / \mathrm{mL}$ of PNA in $50 \mathrm{mM}$ sodium bicarbonate buffer, $\mathrm{pH} 9.5$, blocking was performed with (PBS) $+3 \%$ EIA-grade BSA (Sigma-Aldrich, St. Louis, MO) for $1 \mathrm{~h}$. Equine purified lubricin standard and diluted equine synovial fluid samples $(1: 1000)$ were incubated for $1 \mathrm{~h}$, the plate was washed with PBS $+0.1 \%$ Tween 20 , and monoclonal antibody 9G3 (mAbT401 Anti-Lubricin/Prg4 Clone 9G3) was loaded into the plate at 1:2500 dilution for $1 \mathrm{~h}$. Following a wash cycle as above, goat anti-mouse IgGhorseradish peroxidase (EMD Millipore, Darmstadt, Germany) was added to each well at a 1:4000 dilution for $1 \mathrm{~h}$. Washing three times in PBS $+0.1 \%$ Tween 20 , with a final rinse in PBS alone, was performed. TMB reagent was added (Pierce, Rockford, IL), the reaction was stopped with $1 \mathrm{~N} \mathrm{H2SO} 4$, and absorbance was measured at $450 \mathrm{~nm}$ with $540 \mathrm{~nm}$ background subtraction. The intra-assay coefficient of variation for the lubricin assay was $11.6 \%$, and the samples reading higher than the upper limit of detection of the assay due to oversaturation were assigned a value of $2000 \mu \mathrm{g} / \mathrm{mL}$.

\section{Hyaluronic acid quantification - ELISA and gels}

Synovial fluid HA concentration was measured at all time points using a commercially available HA ELISA (Hyaluronan DuoSet ELISA, Cat\#: DY3614-05, R\&D Systems, Minneapolis, MN) [72]. The distribution of HA molecular weights was determined by gel electrophoresis in a similar manner to that described previously [73]. Synovial fluid samples were diluted 1:15 with phosphate buffered saline and incubated overnight with $75 \mu \mathrm{g} / \mathrm{mL}$ proteinase $\mathrm{k}$ (Proteinase K, recombinant, PCR grade, Roche Applied Science, Mannheim, Germany). Samples and standards, HiLadder (0.5-1.5 MDa) and Mega-HA Ladder (1.5-6.1 MDa; AMS Biotechnology Limited, Cambridge, MA) were loaded onto a $0.5 \%$ agarose gel and run at $57 \mathrm{~V}$ for $8 \mathrm{~h}$. Gels were stained for $24 \mathrm{~h}$ in $0.005 \%$ Stains-All (Sigma-Aldrich, St. Louis, MO) in 50\% ethanol and de-stained in $10 \%$ ethanol for $24 \mathrm{~h}$ with final destaining occurring on exposure to ambient light. Images of gels acquired using a Bio-Rad VersaDoc Imaging System (Hercules, CA) with relative band intensity calculated using Fiji Software (ImageJ). The intra-assay coefficient of variation for the HA ELISA was 9.1\%.

\section{Histological processing}

At day 35 post-induction of synovitis or post-lavage, a $2-3 \mathrm{~mm}$ sample of synovial membrane was obtained using a Ferris-Smith rongeur via standing arthrotomy from either the MCJ or the TCJ joint. Sections were fixed in $10 \%$ formaldehyde for a minimum of 3 days, dehydrated in alcohol, cleared in xylene, paraffin embedded and sectioned at $6 \mu \mathrm{m}$ [74]. Slides were stained as one batch with haemotoxylin and eosin for basic cell identification, then evaluated by three blinded assessors.

\section{Chemokine multiplex assay}

The equine chemokine multiplex assay has been validated and is performed at the Animal Health Diagnostic Center at Cornell University. The fluorescent beadbased assay simultaneously quantifies six equine cytokines/chemokines (IL-1 $\beta$, TNF- $\alpha$, CCL2, CCL3, CCL5, and CCL11) using pairs of monoclonal antibodies (mAbs) for detection of each equine chemokine. The procedures of coupling mAbs to the fluorescent beads (Luminex Corp., Austin, TX, USA) and performing the 
different steps of the assay were previously described in detail for other equine cytokines [75] and were identical for this assay. In brief, the following beads were coupled to mAbs: bead 33 with equine TNF- $\alpha$ mAb 292-1, bead 34 with equine CCL11 mAb 24, bead 35 with IL-1 $\beta$ mAb 84-2, bead 36 with CCL5 mAb 91-1, bead 37 with CCL2 mAb 104-2, and bead 42 with CCL3 mAb 77-2. Specificity to respective chemokine and recognition of the native proteins were confirmed for all mAbs [43] before they were used in the multiplex assay.

All six recombinant equine proteins were expressed in mammalian cells as IL-4 fusion proteins [43, 76]. For the assay runs, a mixture of the six recombinant chemokines was included in different concentrations (5-fold dilutions in PBS with $1 \%(\mathrm{w} / \mathrm{v})$ BSA and $0.05 \%(\mathrm{w} / \mathrm{v})$ sodium azide (blocking buffer)) to create standard curves for quantification of all six chemokines in equine samples. Joint samples were diluted 1:2 in blocking buffer. Millipore Multiscreen HTS plates (Millipore, Danvers, MA) were soaked with PBS with $0.1 \%(\mathrm{w} / \mathrm{v})$ BSA, $0.02 \%(\mathrm{v} / \mathrm{v})$ Tween 20 and $0.05 \%(\mathrm{w} / \mathrm{v})$ sodium azide (PBS-T) using a ELx50 plate washer (Biotek Instruments Inc., Winooski, VT) for $2 \mathrm{~min}$. The solution was aspirated from the plates and $50 \mu \mathrm{l}$ of each diluted standard dilution or the samples were applied to the plates. Then, $50 \mu \mathrm{l}$ of bead solution, containing $5 \times 10^{3}$ beads per bead number, was added to each plate well and incubated with the standards or samples for $30 \mathrm{~min}$ on a shaker at room temperature. The plates were washed with PBS-T and $50 \mu$ of the equine detection antibody mixture diluted in blocking buffer was added to each well and incubated for $30 \mathrm{~min}$ as above. The detection antibody mixtures included six biotinylated mAbs: TNF- $\alpha$ mAb 48-1, CCL11 mAb 25, IL-1 $\beta$ mAb 62-7, CCL 5 mAb 46-1, CCL2 mAb 49, and CCL3 mAb 289-2 [43]. Afterwards plates were washed again and $50 \mu \mathrm{l}$ of streptavidinphycoerythrin (Invitrogen, Carlsbad, CA) was added to the plates for another $30 \mathrm{~min}$ incubation as above. Plates were washed for a last time, beads were resuspended in $100 \mu \mathrm{l}$ of blocking buffer, and the plates were placed on the shaker for $15 \mathrm{~min}$. The assay was analyzed in a Luminex 200 instrument (Luminex Corp., Austin, TX, USA). The data were reported as median fluorescent intensities. For standard curve fitting and subsequent calculation of the chemokine concentrations in samples the logistic $5 p$ formula $\left(y=a+b /\left(1+(x / c)^{\wedge} d\right)^{\wedge} f\right)$ was used (Luminex 200 Integrated System). Chemokine concentrations were reported in $\mathrm{pg} / \mathrm{ml}$. For TNF- $\alpha$ and IL- $1 \beta$ the non-detectable values (0) were set to 1 for analysis.

\section{Dimethylmethylene blue (DMMB) assay}

Synovial fluid samples were tested at all time points for sulfated glycosaminoglycan (sGAG) concentration using a 1,9-dimethylmethylene blue (DMMB) assay. DMMB dye was prepared by combining $16 \mathrm{mg}$ DMMB dye (Sigma-Aldrich, St. Louis, MO) with $5 \mathrm{~mL} \mathrm{95 \%} \mathrm{ethanol}$ and incubating at room temperature for $30 \mathrm{~min}$. Two milliliters of $\mathrm{pH} 3.5$ formate buffer was added to solution, and the total volume was adjusted to $1 \mathrm{~L}$ with water. The dye was stored at room temperature, protected from light. Synovial fluid samples were incubated at $37^{\circ} \mathrm{C}$ with $30 \mathrm{U} /$ $\mathrm{mL}$ Streptomyces hyaluronidase (Sigma-Aldrich, St. Louis, $\mathrm{MO}$ ) for $1 \mathrm{~h}$ and were vortexed every $20 \mathrm{~min}$ during the digestion period. Digested samples were diluted to a final concentration of 1:30 in water. A solution of chondroitin 4sulfate (Sigma-Aldrich, St. Louis, MO) was used as a standard in a range of concentrations from $2.5 \mu \mathrm{g} / \mathrm{mL}$ to $30 \mu \mathrm{g} /$ $\mathrm{mL}$. Milli-Q water was used as a blank. All samples, standards, and blanks were plated in duplicate at a volume of $50 \mu \mathrm{L}$ on a transparent 96-well plate (Corning Inc., Corning, NY). After all samples were applied, the plate was agitated for $60 \mathrm{~s}$ on an orbital shaker (Bellco Glass Inc., Vineland, NJ). Two hundred microliters of DMMB dye was then added to each well of the plate using a multi-channel pipette, and absorbance was immediately read at $540 \mathrm{~nm}$ using a Spark $10 \mathrm{M}$ plate reader (Tecan Austria $\mathrm{GmbH}$, Grödig, Austria).

\section{$\mathrm{PGE}_{2}$ ELISA}

Synovial fluid concentration of $\mathrm{PGE}_{2}$ was evaluated at all time points as previously described [30, 32]. In brief, $250 \mu \mathrm{L}$ of synovial fluid (SF) was mixed with $250 \mu \mathrm{L}$ of $80 \%$ ethanol and $5 \mu \mathrm{L}$ of glacial acetic acid. After incubation, for $5 \mathrm{~min}$ at room temperature, and centrifugation (6000 rpm, $8 \mathrm{~min}$ ), the supernatant was loaded onto Ethyl $\mathrm{C} 2$ mini-columns (Agilent Technologies, Santa Clara, CA) that had been equilibrated with $10 \%$ ethanol. The $\mathrm{PGE}_{2}$-containing minicolumns were washed with $\mathrm{MQ}-\mathrm{H}_{2} \mathrm{O}$ and hexane sequentially. The $\mathrm{PGE}_{2}$ was eluted with two replicates of $375 \mu \mathrm{L}$ of ethyl acetate. The combined $750 \mu \mathrm{L}$ eluate was dried in a Speed Vacuum (Speed Vac Plus, SC110A, SAVANT) and the $\mathrm{PGE}_{2}$ powder was stored in at $-70{ }^{\circ} \mathrm{C}$. The $\mathrm{PGE}_{2}$ concentration in SF samples were measured with a highly sensitive and competitive PGE $_{2}$ ELISA kit (Enzo Life Sciences, Inc., Farmingdale, NY). The $\mathrm{PGE}_{2}$ powder derived from $250 \mu \mathrm{L}$ of synovial fluid was resuspended in $250 \mu \mathrm{L}$ of $\mathrm{PGE}_{2}$ assay buffer. Then, $100 \mu \mathrm{L}$ of the $\mathrm{PGE}_{2}$ solution was added in duplicate to the goat anti-mouse IgG microtiter plate. After being bound with the kit conjugate/antibody and wash, the plate was read at $405 \mathrm{~nm}$ with a background reading at $570 \mathrm{~nm}$ using SPARK $10 \mathrm{M}$ microplate reader (TECAN, Zürich, Switzerland). The $\mathrm{PGE}_{2}$ levels in SF were evaluated using 4-parameter standard curve with the $\mathrm{x}$-axis at Log scale. If the absorbance reading at $405 \mathrm{~nm}$ was above the standard range (maximum $2500 \mathrm{pg} / \mathrm{mL}$ ), the $\mathrm{PGE}_{2}$ concentration was calculated as the maximum standard value $(2500 \mathrm{pg} / \mathrm{mL})$. The intra-assay coefficient of variation for the $\mathrm{PGE}_{2}$ ELISA was $7 \%$. 


\section{Microrheology}

Synovial fluid viscosity was measured with particle tracking microrheology. $0.5 \mu \mathrm{m}$ yellow-green fluorescent beads (FluoSpheres ${ }^{\text {Tx }}$ Carboxylate-Modified Microspheres, $0.5 \mu \mathrm{m}$, yellow-green fluorescent) were diluted in a 1:50 ratio with water. The diluted beads were then mixed with synovial fluid in a 1:50 ratio, totaling $20 \mu \mathrm{l}$. Samples were loaded into wells of silicone gaskets (Grace Bio-Labs Press-To-Seal silicone isolator, No PSA 24-2 mm diam. $\times 0.5 \mathrm{~mm}$ depth) which were presssealed on $35 \mathrm{~mm}$ glass-bottom dishes (Cellvis D35-20$1.5-\mathrm{N}$ ). The sample was covered with a \#1.5 glass coverslip to prevent evaporation and placed on an inverted fluorescence microscope (IX81, Olympus) equipped with a 60x NA 1.2 water-immersion objective and with $1 x$ magnification. Fluorescence excitation by a $488 \mathrm{~nm}$ laser (Sapphire-LP, Coherent) was expanded $8.3 \mathrm{x}$ before focusing on the objective back aperture by a $300 \mathrm{~mm}$ tube lens (ThorLabs). Fluorescence emission was imaged with an EMCCD (897 Ultra, Andor) through a standard FITC filter set (Chroma) using the Micro-Manager software package (Open Imaging). Three 30-s videos were taken per sample, with several locations in each sample targeted to collect particle movement data. Each video contained approximately 15 particles in the frame. Analysis of motion was done using the Trackpy Python package. Images were acquired at $16 \mathrm{~Hz}$.

\section{RNA extraction/gene expression}

Gene expression was examined in synovial membrane (SM) samples of horses (Equus caballus) collected at day 35 post-induction of synovitis or intra-articular lavage and in synovial fluid cell pellets collected at 12 - and $24 \mathrm{~h}$ post-induction. RNA was extracted from synovial membrane samples using the RNeasy Lipid Tissue Mini kit (QIAGEN, Gaithersburg, MD). The synovial fluid cell pellets were centrifuged as described above, the supernatant was aliquoted for freezing, and the SF cell pellet was suspended in $0.5 \mathrm{~mL}$ of TRIzol Reagent (ThermoFisher Sci., Waltham, MA). Crude RNA was extracted following the instruction manual of TRIzol Reagent. An RNA Clean and Concentrator kit (Zymo Research, Irvine, CA) was employed to further purify and concentrate the SF cell pellet RNA. Any remaining genomic DNA in the RNA extract was removed by DNase I digestion on-column for both SM and SF cell pellet RNA. RNA concentrations and quality were determined using a 16-well NanoQuant plate and a SPARK $10 \mathrm{M}$ microplate reader (TECAN, Zürich, Switzerland). The expression levels of three genes (PRG4, IL1 $\beta$ and HAS2 encoding for Hyaluronan synthase 2) in $\mathrm{SM}$ and four genes (PRG4, TSG6 encoding for TNF-stimulated gene 6 protein, HAS1 and HAS3) in SF cell pellets were analyzed.
Gene expression was detected by quantitative realtime PCR (qRT-PCR) using the Applied Biosystems Real-Time PCR ViiA 7 system (Applied Biosystems, Foster City, CA). All samples were analyzed in duplicate using the Power SYBR green RNA-to- $C_{T}$ one-step kit (Applied Biosystem Inc., Carlsbad, CA). Primers (Supplemental Data 3) were selected from publications [48, 59] or designed by NCBI Primer 3 \& Blast or with DNASTAR LASERGENE.

For qRT-PCR, $30 \mathrm{ng}$ of SM total RNA or $15 \mathrm{ng}$ of SF cell pellet RNA was used in $20 \mu \mathrm{L}$ of reaction mix containing SYBR RT-PCR mix and RT enzyme mix. The qRT-PCR was run at $48^{\circ} \mathrm{C}$ for $30 \mathrm{~min}$ and at $95^{\circ} \mathrm{C}$ for $10 \mathrm{~min}$, followed by $40 \mathrm{cycles}$ of $95^{\circ} \mathrm{C} / 15 \mathrm{~s}$ and $60^{\circ} \mathrm{C} / 1$ min. Successful qRT-PCR was verified via analysis of both dissociation curves and agarose gel electrophoresis. All values were normalized to the housekeeping gene 18S rRNA. Relative gene expression was analyzed using the $2^{-\Delta C T}$ method [77, 78], where $\Delta C_{T}=C_{T}$ (gene of interest)- $\mathrm{C}_{\mathrm{T}}\left(18 \mathrm{~S}\right.$ rRNA) and calculated as $\left(10^{4}-10^{7}\right) \times$ $2^{-\Delta C T}[77]$.

\section{Statistical analysis}

All analyses were conducted with Stata 16.1MP, StataCorp, College Station TX, with two-sided tests of hypotheses and a $p$-value $<0.05$ as the criterion for statistical significance. Descriptive analyses include computation of means (with 95\% confidence intervals [95\% CI]), standard deviations, medians, interquartile ranges (IQR) of continuous variables and tabulation of categorical variables. Tests of normal distribution (Shapiro-Wilk test) were performed to determine extent of skewness. Frequency counts and percentages were used for categorical variables such as signalment and others.

Inference statistical analysis was based on a multilevel mixed-effects model with interaction between treatment group and categorical time as the fixed effects and age as a confounder. Random effects were set on the level of joint nested within leg which in term was nested within specific animal. All random effects were considered random intercepts. Robust estimation of the variance was used to permit for departures from normality of the outcome. Post-hoc pairwise comparisons were conducted to estimate the marginal (model adjusted) effects. Least significant difference (LSD) was used to adjust for multiple comparisons. The figures presented in this paper depict the marginal means used in the statistical model and not the raw data which is presented in Supplemental Data 2.

\footnotetext{
Abbreviations

OA: Osteoarthritis; IL-1ß: Interleukin 1 beta; CCL: Chemokine receptor ligand; HA: Hyaluronic acid; TNFa: Tumor necrosis factor alpha; $\mathrm{PGE}_{2}$ : Prostaglandin $E_{2} ;$ SF: Synovial fluid; SM: Synovial membrane; LPS: Lipopolysaccharide; MMPs: Matrix metalloproteases; ADAMTS4: A disintegrin and metalloproteinase with thrombospondin motif 4; TP: Total protein; sGAG: Sulfated glycosaminoglycans; ELISA: Enzyme linked immunosorbent
} 
assay; RT-PCR: Reverse transcriptase polymerase chain reaction; PMN: Polymorphonuclear cells; WBC: White blood cells; TCJ: Tarsocrural joint; MCJ: Middle carpal joint; AAEP: American Association of Equine Practitioners; PBS: Phosphate buffered saline; ACB: Accessory carpal bone; PNA: Peanut agglutinin; HR: Heart rate; T: Temperature; HMW HA: High molecular weight hyaluronic acid; TSG6: Tumor necrosis factor-stimulated gene-6 protein; HAS1-3: Hyaluronan synthase 1-3

\section{Supplementary Information}

The online version contains supplementary material available at https://doi. org/10.1186/s12917-021-02873-2

Additional file 1: Supplemental Data 1. Heart rate $(H R)$, temperature $(T)$, respiratory rate $(R R)$, and joint circumference $(J C)$ following IL-1 $\beta$ induced synovitis or intra-articular lavage. Graphs depicting changes in heart rate, temperature, respiratory rate and joint circumference following induction of synovitis and intra-articular lavage.

Additional file 2: Supplemental Data 2. Mean and standard error of the mean for the non-adjusted parameters measured in synovial fluid following synovitis induction and intra-articular lavage of the MCJ and TCJ. Data table of the means and standard error of the means for the unadjusted data described in the paper

Additional file 3: Supplemental Data 3. Equine gene names, accession numbers, primer sequences and amplicon sizes for qRT-PCR. Table of primers used for gene expression analysis used in this paper.

\section{Authors' contributions}

AW contributed to study design, collected and analyzed the data and was a major contributor in writing the manuscript. DF and JS contributed to the acquisition, analysis and interpretation of data and assisted with manuscript preparation. DS and BW contributed to the data analysis and assisted with manuscript preparation. SS, KC, AD, and CR all contributed to data collection and assisted with writing the manuscript. EC, HF, MC, and MP contributed to data collection and analysis. HR designed the study, contributed to data collection, analysis, and interpretation and was a major contributor in the writing of the manuscript. All authors read and approved the final manuscript.

\section{Funding}

Research was supported by the Harry M. Zweig Memorial Fund for Equine Research. No role in the design of the study, collection, analysis, or interpretation of the data was performed by this granting agency. The mAbs for the chemokine multiplex assay were developed with funding from USDA/NIFA grant \#2015-67015-23072 'Equine Immune Reagents: Development of monoclonal antibodies to improve the analysis of immunity in horses' and USDA/NIFA grant \#2019-67015-29833 'Development of Equine Immune Reagents'.

\section{Availability of data and materials}

The datasets used and/or analyzed during the current study are available from the corresponding author on reasonable request.

\section{Declarations}

\section{Ethics approval and consent to participate}

All protocols were approved by the Cornell University Institutional Animal Care and Use Committee. All methods were carried out in accordance with relevant guidelines and regulations for the use of animal subjects. The study was carried out in compliance with the ARRIVE guidelines.

\section{Consent for publication}

Not applicable.

\section{Competing interests}

The authors declare that they have no competing interests.

\section{Author details}

'Department of Clinical Sciences, College of Veterinary Medicine, Cornell University, Ithaca, NY, USA. ${ }^{2}$ Department of Biostatistics, School of Veterinary Medicine, University of Pennsylvania, Philadelphia, PA, USA. ${ }^{3}$ Robert Frederick
Smith School of Chemical and Biomolecular Engineering, Cornell University, Ithaca, NY, USA. ${ }^{4}$ Department of Population Medicine and Diagnostic Sciences, College of Veterinary Medicine, Cornell University, Ithaca, NY, USA

Received: 7 February 2021 Accepted: 30 March 2021

Published online: 12 May 2021

\section{References}

1. Goodrich LR, Nixon AJ. Medical treatment of osteoarthritis in the horse - a review. Vet J. 2006;171(1):51-69. https://doi.org/10.1016/j.tvjl.2004.07.008.

2. Rossdale PD, Hopes R, Digby NJ, Offord K. Epidemiological study of wastage among racehorses 1982 and 1983. Vet Rec. 1985;116(3):66-9. https://doi. org/10.1136/vr.116.3.66.

3. Martins MC, Peffers MJ, Lee K, Rubio-Martinez LM. Effects of stanozolol on normal and IL-1ß-stimulated equine chondrocytes in vitro. BMC Vet Res. 2018;14(1):1-7. https://doi.org/10.1186/s12917-018-1426-Z.

4. Machado TSL, Massoco CO, Silva LCLC, Fülber J, Moreira JJ, Baccarin RYA. Effects of blood-derived products and sodium hyaluronate on equine synovial fluid cells and on synovial fluid from osteochondrotic joints of horses after arthroscopy and administration of treatment. Am J Vet Res. 2019;80(7):646-56. https://doi.org/10.2460/ajvr.80.7.646.

5. Spadari A, Rinnovati R, Babbini S, Romagnoli N. Clinical evaluation of intraarticular administration of stanozolol to manage lameness associated with acute and chronic osteoarthritis in horses. J Equine Vet Sci. 2015;35(2):10510. https://doi.org/10.1016/j.jevs.2014.12.003.

6. Perrone G, Lastra Y, González C, Caggiano N, Giménez R, Pareja R, et al. Treatment with platelet lysate inhibits proteases of synovial fluid in equines with osteoarthritis. J Equine Vet Sci. 2020;88:102952. https://doi.org/10.1016/ j.jevs.2020.102952

7. Gilbertie JM, Long JM, Schubert AG, Berglund AK, Schaer TP, Schnabel LV. Pooled platelet-rich plasma lysate therapy increases synoviocyte proliferation and hyaluronic acid production while protecting chondrocytes from synoviocyte-derived inflammatory mediators. Front Vet Sci. 2018:5:150. https://doi.org/10.3389/fvets.2018.00150

8. Fu X, Lin L, Zhang J, Yu C. Assessment of the efficacy of joint lavage in rabbits with osteoarthritis of the knee. J Orthop Res. 2009;27(1):91-6. https:// doi.org/10.1002/jor.20720.

9. Cokelaere S, Malda J, van Weeren R. Cartilage defect repair in horses: current strategies and recent developments in regenerative medicine of the equine joint with emphasis on the surgical approach. Vet J. 2016;214:61-71. https://doi.org/10.1016/j.tvjl.2016.02.005.

10. Cousty M, David Stack J, Tricaud C, David F. Effect of arthroscopic lavage and repeated intra-articular administrations of antibiotic in adult horses and foals with septic arthritis. Vet Surg. 2017;46(7):1008-16. https://doi.org/1 0.1111 vsu. 12696 .

11. Baldwin CM, Smith MRW, Allen S, Wright IM. Radiographic and arthroscopic features of third carpal bone slab fractures and their impact on racing performance following arthroscopic repair in a population of racing thoroughbreds in the UK. Equine Vet J. 2020;52(2):213-8. https://doi.org/1 $0.1111 /$ evj.13155.

12. Henderson $\mathrm{E}$, Clements $\mathrm{DN}$, Johnson $\mathrm{Cl}$. An in vitro study of the effect of the optimal irrigation solution conditions during canine articular surgery. Vet Res Commun. 2020;44(1):1-7. https://doi.org/10.1007/s11259-019-09765-9.

13. Teeple E, Karamchedu NP, Larson KM, Zhang L, Badger GJ, Fleming BC, et al. Arthroscopic irrigation of the bovine stifle joint increases cartilage surface friction and decreases superficial zone lubricin. J Biomech. 2016;49(13):310610. https://doi.org/10.1016/j.jbiomech.2016.07.024.

14. Mcllwraith CW, Nixon AJ, Wright IM. Diagnostic and surgical arthroscopy in the horse. 4th ed; 2015

15. Rossetti RB, Massoco CDO, Penna ACA, Correia de Sllva LCL. An experimental study to compare inflammatory response due to liquid or gas joint distension in horses submitted to arthroscopy 1 Estudo experimental para comparar a resposta inflamatória decorrente da distensão líquida ou gasosa em ca. Acta Cir Bras. 2012;27(12):848-54. https://doi.org/10.1590/S01 02-86502012001200004.

16. Das S, Banquy X, Zappone B, Greene GW, Jay GD, Israelachvili JN. Synergistic interactions between grafted hyaluronic acid and lubricin provide enhanced wear protection and lubrication. Biomacromolecules. 2013;14(5):1669-77. https://doi.org/10.1021/bm400327a.

17. Musumeci G, Trovato FM, Loreto C, Leonardi R, Szychlinska MA, Castorina S, et al. Lubricin expression in human osteoarthritic knee meniscus and 
synovial fluid: a morphological, immunohistochemical and biochemical study. Acta Histochem. 2014;116(5):965-72. https://doi.org/10.1016/j.acthis.2 014.03 .011$.

18. Jay GD, Waller KA. The biology of lubricin: near frictionless joint motion. Matrix Biol. 2014;39:17-24. https://doi.org/10.1016/j.matbio.2014.08.008.

19. Svala E, Jin C, Rüetschi U, Ekman S, Lindahl A, Karlsson NG, et al. Characterisation of lubricin in synovial fluid from horses with osteoarthritis. Equine Vet J. 2017;49(1):116-23. https://doi.org/10.1111/evj.12521.

20. Feeney E, Peal BT, Inglis JE, et al. Temporal changes in synovial fluid composition and elastoviscous lubrication in the equine carpal fracture model. J Orthop Res. 2019:jor.24281. https://doi.org/10.1002/jor.24281.

21. Waller KA, Zhang LX, Elsaid KA, Fleming BC, Warman ML, Jay GD. Role of lubricin and boundary lubrication in the prevention of chondrocyte apoptosis. Proc Natl Acad Sci U S A. 2013;110(15):5852-7. https://doi.org/1 0.1073/pnas.1219289110.

22. Mathies B. Effects of Viscoseal, a synovial fluid substitute, on recovery after arthroscopic partial meniscectomy and joint lavage. Knee Surg Sport Traumatol Arthrosc. 2006;14(1):32-9. https://doi.org/10.1007/s00167-005-0625-x.

23. Hempfling $\mathrm{H}$. Intra-articular hyaluronic acid after knee arthroscopy: a twoyear study. Knee Surg Sport Traumatol Arthrosc. 2007;15(5):537-46. https://doi.org/10.1007/s00167-006-0260-1.

24. Sellam J, Berenbaum F. The role of synovitis in pathophysiology and clinical symptoms of osteoarthritis. Nat Rev Rheumatol. 2010;6(11):625-35. https://doi.org/10.1038/nrrheum.2010.159.

25. Hawkins DL, MacKay RJ, Gum GG, Colahan PT, Meyer JC. Effects of intraarticularly administered endotoxin on clinical signs of disease and synovial fluid tumor necrosis factor, interleukin 6, and prostaglandin E2 values in horses. Am J Vet Res. 1993;54(3):379-86.

26. Palmer $\mathrm{L}$, Bertone AL. Experimentally-induced synovitis as a model for acute synovitis in the horse. Equine Vet J. 1994;26(6):492-5. https://doi.org/1 0.1111/j.2042-3306.1994.tb04056.x.

27. Palmer JL, Bertone AL, Malemud CJ, Mansour J. Biochemical and biomechanical alterations in equine articular cartilage following an experimentally-induced synovitis. Osteoarthr Cartil. 1996;4(2):127-37. https:// doi.org/10.1016/S1063-4584(05)80321-8.

28. Todhunter PG, Kincaid SA, Todhunter RJ, Kammermann JR, Johnstone B, Baird AN, et al. Immunohistochemical analysis of an equine model of synovitis-induced arthritis. Am J Vet Res. 1996;57(7):1080-93.

29. Ludwig EK, Brandon Wiese R, Graham MR, Tyler AJ, Settlage JM, Werre SR, et al. Serum and synovial fluid serum amyloid a response in equine models of synovitis and septic arthritis. Vet Surg. 2016;45(7):859-67. https://doi.org/1 0.1111/vsu. 12531 .

30. Colbath AC, Dow SW, Hopkins LS, Phillips JN, Mcllwraith CW, Goodrich LR. Induction of synovitis using Interleukin-1 Beta: are there differences in the response of middle carpal joint compared to the tibiotarsal joint? Front Vet Sci. 2018;5(August):1-9. https://doi.org/10.3389/fvets.2018.00208.

31. Nelson BB, King MR, Frisbie DD. Assessment of a novel equine tarsocrural experimental joint disease model using recombinant interleukin-1 $\beta$ and arthroscopic articular sampling of the medial malleolus of the tibia on the standing sedated horse. Vet J. 2017;229:54-9. https://doi.org/10.1016/j.tvjl.2 017.10.021.

32. Ross TN, Kisiday JD, Hess T, Mcllwraith CW. Evaluation of the inflammatory response in experimentally induced synovitis in the horse: a comparison of recombinant equine interleukin 1 beta and lipopolysaccharide. Osteoarthr Cartil. 2012;20(12):1583-90. https://doi. org/10.1016/j.joca.2012.08.008.

33. Scott I, Midha A, Rashid U, Ball S, Walding A, Kerry P, et al. Correlation of gene and mediator expression with clinical endpoints in an acute interleukin-1 beta-driven model of joint pathology. Osteoarthr Cartil. 2009; 17(6):790-7. https://doi.org/10.1016/j.joca.2008.09.016.

34. Jay GD, Elsaid KA, Zack J, Robinson K, Trespalacios F, Cha CJ, et al. Lubricating ability of aspirated synovial fluid from emergency department patients with knee joint synovitis. J Rheumatol. 2004;31(3):557-64.

35. Irwin RM, Feeney E, Secchieri C, et al. Distinct tribological endotypes of pathological human synovial fluid reveal characteristic biomarkers and variation in efficacy of viscosupplementation at reducing local strains in articular cartilage. Osteoarthr Cartil. 2020. https://doi.org/10.1016/j.joca.2020.02.029.

36. Bertuglia A, Pagliara E, Grego E, Ricci A, Brkljaca-Bottegaro N. Proinflammatory cytokines and structural biomarkers are effective to categorize osteoarthritis phenotype and progression in Standardbred racehorses over five years of racing career. BMC Vet Res. 2016;12:1-15.
37. Ma TW, Li Y, Wang GY, Li XR, Jiang RL, Song XP, et al. Changes in synovial fluid biomarkers after experimental equine osteoarthritis. J Vet Res. 2017; 61(4):503-8. https://doi.org/10.1515/jvetres-2017-0056.

38. Luster A. Chemokines - chemotactic cytokines that mediate inflammation. N Engl J Med. 1998;338(7):436-45. https://doi.org/10.1056/NEJM1998021233 80706.

39. Zlotnik A, Yoshie O. The chemokine superfamily revisited. Immunity. 2012; 36(5):705-16. https://doi.org/10.1016/j.immuni.2012.05.008.

40. David KS, Oliveira ERA, Horta BAC, Valente AP, De Paula VS. Insights into CC chemokine ligand 2/chemokine receptor 2 molecular recognition: a step forward toward antichemotactic agents. Biochemistry. 2017;56(25):3197-210. https://doi.org/10.1021/acs.biochem.7b00129.

41. Hosokawa Y, Hosokawa I, Ozaki K, Matsuo T. Transforming growth factor- $\beta 1$ increases C-C chemokine ligand 11 production in interleukin 4-stimulated human periodontal ligament cells. Cell Biol Int. 2018:42(10):1395-400. https://doi.org/10.1002/cbin.11030.

42. Haringman JJ, Ludikhuize J, Tak PP. Chemokines in joint disease: the key to inflammation? Ann Rheum Dis. 2004;63(10):1186-94. https://doi.org/10.113 6/ard.2004.020529.

43. Schnabel CL, Wemette M, Babasyan S, Freer H, Baldwin C, Wagner B. C-C motif chemokine ligand (CCL) production in equine peripheral blood mononuclear cells identified by newly generated monoclonal antibodies. Vet Immunol Immunopathol. 2018;204(April):28-39. https://doi.org/10.1016/j. vetimm.2018.09.003.

44. Mantovani A, Sica A, Sozzani S, Allavena P, Vecchi A, Locati M. The chemokine system in diverse forms of macrophage activation and polarization. Trends Immunol. 2004;25(12):677-86. https://doi.org/10.1016/j.it.2004.09.015.

45. Kindstedt E, Holm CK, Sulniute R, Martinez-Carrasco I, Lundmark R, Lundberg P. CCL11, a novel mediator of inflammatory bone resorption. Sci Rep. 2017; 7(1):1-10. https://doi.org/10.1038/s41598-017-05654-w.

46. Endres M, Andreas K, Kalwitz G, Freymann U, Neumann K, Ringe J, et al. Chemokine profile of synovial fluid from normal, osteoarthritis and rheumatoid arthritis patients: CCL25, CXCL10 and XCL1 recruit human subchondral mesenchymal progenitor cells. Osteoarthr Cartil. 2010;18(11): 1458-66. https://doi.org/10.1016/j.joca.2010.08.003.

47. Peal BT, Gagliardi R, Su J, Fortier LA, Delco ML, Nixon AJ, et al. Synovial fluid lubricin and hyaluronan are altered in equine osteochondral fragmentation, cartilage impact injury and full-thickness cartilage defect models. J Orthop Res. 2020:0-3. https://doi.org/10.1002/jor.24597.

48. Reesink HLL, Watts AEE, Mohammed HOO, Jay GDD, Nixon AJJ. Lubricin/ proteoglycan 4 increases in both experimental and naturally occurring equine osteoarthritis. Osteoarthr Cartil. 2017;25(1):128-37. https://doi.org/1 0.1016/j.joca.2016.07.021.

49. Antonacci JM, Schmidt TA, Serventi LA, Cai MZ, Shu YYL, Schumacher BL, et al. Effects of equine joint injury on boundary lubrication of articular cartilage by synovial fluid: role of hyaluronan. Arthritis Rheum. 2012;64(9): 2917-26. https://doi.org/10.1002/art.34520.

50. Sotelo EDP, Vendruscolo CP, Fülber J, et al. Effects of joint lavage with dimethylsulfoxide on LPS-induced synovitis in horses-clinical and laboratorial aspects. Vet Sci. 2020;7(2). https://doi.org/10.3390/NETSCI7020057.

51. Blewis ME, Nugent-Derfus GE, Schmidt TA, Schumacher BL, Sah RL. A model of synovial fluid lubricant composition in normal and injured joints. Eur Cell Mater. 2007:13:26-39. https://doi.org/10.22203/eCM.v013a03.

52. Neuenschwander HM, Moreira JJ, Vendruscolo CP, Fülber J, Seidel SRT, Michelacci YM, et al. Hyaluronic acid has chondroprotective and jointpreserving effects on LPS-induced synovitis in horses. J Vet Sci. 2019;20(6): 1-15. https://doi.org/10.4142/jvs.2019.20.e67.

53. Jin C, Ekwall A-KH, Bylund J, Björkman L, Estrella RP, Whitelock JM, et al Human synovial lubricin expresses sialyl Lewis $\mathrm{x}$ determinant and has Lselectin ligand activity. J Biol Chem. 2012;287(43):35922-33. https://doi.org/1 $0.1074 /$ jbc.M112.363119.

54. Wanderling C, Liles J, Davis E, Schmitt D, Statz S, Guler N, et al. Levels of matrix-degrading enzymes and lubricin in patients with degenerative joint disease requiring arthroplasty. Clin Appl Thromb. 2018;24(1):41-6. https:// doi.org/10.1177/1076029617724231

55. Elsaid KA, Jay GD, Warman ML, Rhee DK, Chichester CO. Association of articular cartilage degradation and loss of boundary-lubricating ability of synovial fluid following injury and inflammatory arthritis. Arthritis Rheum. 2005;52(6):1746-55. https://doi.org/10.1002/art.21038.

56. Menarim BC, Gillis KH, Oliver A, Mason C, Werre SR, Luo X, et al. Inflamed synovial fluid induces a homeostatic response in bone marrow 
mononuclear cells in vitro: implications for joint therapy. FASEB J. 2020; 34(3):4430-44. https://doi.org/10.1096/fj.201902698R.

57. Bertone AL, Palmer JL, Jones J. Synovial fluid cytokines and eicosanoids as markers of joint disease in horses. Vet Surg. 2001;30(6):528-38. https://doi. org/10.1053/jvet.2001.28430.

58. Ross-Jones TN, Mcllwraith CW, Kisiday JD, Hess TM, Hansen DK, Black J. Influence of an $\mathrm{n}$-3 long-chain polyunsaturated fatty acid-enriched diet on experimentally induced synovitis in horses. J Anim Physiol Anim Nutr (Berl). 2016;100(3):565-77. https://doi.org/10.1111/jpn.12359.

59. Kamm JL, Nixon AJ, Witte TH. Cytokine and catabolic enzyme expression in synovium, synovial fluid and articular cartilage of naturally osteoarthritic equine carpi. Equine Vet J. 2010;42(8):693-9. https://doi.org/10.1111/j.2 042-3306.2010.00140.x.

60. Rubartelli A, Bajetto A, Allavena G, Cozzolino F, Sitia R. Post-translational regulation of interleukin $1 \beta$ secretion. Cytokine. 1993;5(2):117-24. https://doi. org/10.1016/1043-4666(93)90050-F.

61. Wahl K, Adams SB, Moore GE. Contamination of joints with tissue debris and hair after arthrocentesis: the effect of needle insertion angle, spinal needle gauge, and insertion of spinal needles with and without a stylet. Vet Surg. 2012;41(3):391-8. https://doi.org/10.1111/j.1532-950X.2 011.00969.x.

62. Hunt CL, Leatherwood JL, Coverdale JA, Sigler DL, Vogelsang MM, Arnold CE. Effects of repeated arthrocentesis on systemic cytokine expression and leukocyte population in young horses challenged with intra-articular lipopolysaccharide. J Anim Sci. 2019;97(1):184-91. https://doi.org/10.1093/ja s/sky423.

63. Van Den Boom R, Brama PAJ, Kiers GH, DeGroot J, Barneveld A, Van Weeren RR. The influence of repeated arthrocentesis and exercise on matrix metalloproteinase and tumour necrosis factor alpha activities in normal equine joints. Equine Vet J. 2004;36(2):155-9. https://doi.org/10.2746/04251 64044868602.

64. Brama PAJ, Boom R, DEGroot J, Kiers GH, Weeren PR. Collagenase-1 (MMP-1) activity in equine synovial fluid: influence of age, joint pathology, exercise and repeated arthrocentesis. Equine Vet J. 2010;36(1):34-40. https://doi. org/10.2746/0425164044864705.

65. Francoz D, Desrochers A, Latouche JS. Effect of repeated arthrocentesis and single joint lavage on cytologic evaluation of synovial in 5 young calves. Can J Vet Res. 2007;71(2):129-34.

66. White KK, Hodgson DR, Hancock D, Parry BW, Cordell C. Changes in equine carpal joint synovial fluid in response to the injection of two local anesthetic agents. Cornell Vet. 1989;79(1):25-38.

67. Berg RIM, Sykes JE, Kass PH, Vernau W. Effect of repeated arthrocentesis on cytologic analysis of synovial fluid in dogs. J Vet Intern Med. 2009;23(4):8147. https://doi.org/10.1111/j.1939-1676.2009.0340.x.

68. Wisniewski H, Hua J, Poppers DM, Naime D, Vileek J, Cronsteint BN. TNF/L1-inducible protein TSG-6 potentiates plasmin inhibition by inter-alphainhibitor and exerts a strong anti-inflammatory effect in vivo. J Immunol. 1996;156:1609-15.

69. Nishida Y, Knudson CB, Nietfeld JJ, Margulis A, Knudson W. Antisense inhibition of hyaluronan synthase-2 in human articular chondrocytes inhibits proteoglycan retention and matrix assembly. J Biol Chem. 1999; 274(31):21893-9. https://doi.org/10.1074/jbc.274.31.21893.

70. Elsaid KA, Jay GD, Chichester CO. Detection of collagen type II and proteoglycans in the synovial fluids of patients diagnosed with noninfectious knee joint synovitis indicates early damage to the articular cartilage matrix. Osteoarthr Cartil. 2003;11(9):673-80. https://doi.org/10.1016/ S1063-4584(03)00151-1.

71. Elsaid KA, Machan JT, Waller K, Fleming BC, Jay GD. The impact of anterior cruciate ligament injury on lubricin metabolism and the effect of inhibiting tumor necrosis factor alpha on chondroprotection in an animal model. Arthritis Rheum. 2009;60(10):2997-3006. https://doi.org/10.1002/art.24800.

72. Barton Kl, Ludwig TE, Achari Y, Shrive NG, Frank CB, Schmidt TA. Characterization of proteoglycan 4 and hyaluronan composition and lubrication function of ovine synovial fluid following knee surgery. J Orthop Res. 2013;31(10):1549-54. https://doi.org/10.1002/jor.22399.

73. Lee HG, Cowman MK. An agarose gel electrophoretic method for analysis of hyaluronan molecular weight distribution. Anal Biochem. 1994;219(2):27887. https://doi.org/10.1006/abio.1994.1267.

74. Nixon AJ, Begum L, Mohammed HO, Huibregtse B, O'Callaghan MM, Matthews GL. Autologous chondrocyte implantation drives early chondrogenesis and organized repair in extensive full- and partial-thickness cartilage defects in an equine model. J Orthop Res. 2011;29(7):1121-30. https://doi.org/10.1002/jor.21366

75. Wagner B, Freer H. Development of a bead-based multiplex assay for simultaneous quantification of cytokines in horses. Vet Immunol Immunopathol. 2009;127(3-4):242-8. https://doi.org/10.1016/j.vetimm.2008.1 0.313.

76. Wagner B, Hillegas JM, Babasyan S. Monoclonal antibodies to equine CD23 identify the low-affinity receptor for lgE on subpopulations of IgM + and IgG1 + B-cells in horses. Vet Immunol Immunopathol. 2012;146(2):125-34. https://doi.org/10.1016/j.vetimm.2012.02.007.

77. Chan DD, Xiao WF, Li J, de la Motte CA, Sandy JD, Plaas A. Deficiency of hyaluronan synthase 1 (Has1) results in chronic joint inflammation and widespread intra-articular fibrosis in a murine model of knee joint cartilage damage. Osteoarthr Cartil. 2015;23(11):1879-89. https://doi.org/10.1016/j. joca.2015.06.021.

78. Schmittgen TD, Livak KJ. Analyzing real-time PCR data by the comparative C(T) method. Nat Protoc. 2008;3(6):1101-8. https://doi.org/10.1038/nprot.2 008.73 .

\section{Publisher's Note}

Springer Nature remains neutral with regard to jurisdictional claims in published maps and institutional affiliations.
Ready to submit your research? Choose BMC and benefit from:

- fast, convenient online submission

- thorough peer review by experienced researchers in your field

- rapid publication on acceptance

- support for research data, including large and complex data types

- gold Open Access which fosters wider collaboration and increased citations

- maximum visibility for your research: over $100 \mathrm{M}$ website views per year

At BMC, research is always in progress.

Learn more biomedcentral.com/submissions 